\title{
1 Meso-scale modelling of aeolian sediment input to coastal dunes
}

3 Irene Delgado-Fernandez

5 Department of Geography, University of Guelph, Guelph, Ontario, Canada

7 Abstract

8 The collection of a time series coupling hourly wind data (speed and direction)

9 with sand transport over months has provided new insights into the dynamics of

10 transport events that input sediment to the foredune at Greenwich Dunes, Prince

11 Edward Island National Park, Canada. This paper summarises the key aspects of

12 aeolian sediment movement for a period of 9 months and presents a modelling

13 approach for resolving aeolian transport to coastal dunes at the meso-scale. The

14 main hypothesis of the modelling approach is that a small number of key factors

15 control both the occurrence and the magnitude of transport events. Thresholds

16 associated with these factors may be used to filter the time series and isolate

17 potential transport periods over the year. The impacts of nearshore processes

18 are included in the approach as part of the dynamics of coastal dunes, as are

19 supply-limiting factors and trade-offs between fetch distances, angle of wind

20 approach, and beach dimensions. A simple analytical procedure, based on

21 previously published equations, is carried out to assess the general viability of

22 the conceptual approach. Results show that the incorporation of moisture and

23 fetch effects in the calculation of transport for isolated potential transport periods 
24 result in improved predictions of sediment input to the dune. Net changes,

25 measured with three different techniques, suggest that survey data with coarse

26 temporal resolution underestimates the amount of sand input to the dune,

27 because sediment is often removed from the embryo dune and foredune by other

28 processes such as wave scarping. Predictions obtained by the proposed

29 modelling approach are of the same order of magnitude as measured deposition

30 and much less than predicted by models based solely on wind speed and

31 direction. Areas for improvement and alternative modelling approaches, such as

32 probabilistic approaches similar to weather forecasting, are covered in the

33 discussion.

35 Research Highlights

36 - Aeolian sediment input to coastal dunes is not only a function of wind

37 speed.

38 - This work proposes a modelling approach that improves predictions at the

39 meso-scale.

$40 \quad-\quad$ The incorporation of factors such as fetch and moisture improves

$41 \quad$ calculations.

\section{Keywords}

44 Transport events; Beach-dune interaction; Foredune sediment budget; Foredune 45 evolution 
49 Coastal dunes occur at the intersection of two geomorphic systems: the aeolian

50 realm which is necessary to create them and the suite of nearshore processes

51 that have a substantial impact on their evolution. A fundamental aspect of

52 beach-dune interaction is the output of sand from the beach by wind processes,

53 which represents the primary sediment input to foredunes and is essential in

54 calculations of coastal dune budgets (Hesp, 1988a, Psuty, 1988a, Psuty,

$551988 \mathrm{~b}$ and Nickling and Davidson-Arnott, 1990). A wind strong enough to

56 transport sediment is a necessary condition for the creation of coastal dunes

57 (Sherman and Hotta, 1990) as is the determination of a surface shear stress

58 threshold value required to set sediment in motion (Coates and Vitek, 1980).

59 Because of the unique location of coastal dunes within a complex suite of aeolian

60 and nearshore processes, Delgado-Fernandez and Davidson-Arnott

61 (2011) suggest that foredune building occurs within a zone whose lower bound is

62 the minimum wind stress necessary for sand transport and whose upper bound

63 marks the transition to foredune scarping by waves.

64 Sediment input by wind to the adjacent coastal dune system at the meso-scale is

65 usually predicted by incorporating hourly wind speed and direction data

66 measured at standard meteorological stations into sediment transport equations.

67 This procedure often consists of integrating instantaneous transport rate

68 equations (e.g., Bagnold, 1941, Kadib, 1964,Hsu, 1974 and Lettau and Lettau,

69 1977) in relation to time and wind direction (e.g.,Fryberger and Dean, 
70 1979, Kroon and Hoekstra, 1990, Lynch et al., 2008 and Wahid, 2008). The

71 resulting calculations, however, frequently do not agree with observed values of

72 sand deposition on the dunes (e.g., Hunter et al., 1983, Sarre, 1989, Chapman,

731990 and Davidson-Arnott and Law, 1996). Supply-limiting factors are often cited

74 as being responsible for decreasing potential sediment transport rates and thus

75 confounding predictions of sand input to the foredunes (Nickling and Davidson-

76 Arnott, 1990). Variables such as moisture, presence of snow cover, fetch

77 distances, development of gravel lags, surface crusts, and differences in

78 sediment characteristics may limit sediment supply from the beach surface. All of

79 these factors can vary rapidly both in space and time and are subject to a strong

80 seasonal pattern on mid-latitude beaches as a result of storm action, the growth

81 and decay of vegetation, and temperature fluctuations above and below freezing

82 (e.g., Ruz and Meur-Ferec, 2004).

83 Research has focused on identifying the effects of each factor individually on

84 instantaneous transport rates, but there is a lack of understanding of their

85 combined effect over weeks or months (Bauer and Sherman, 1999). Not all

86 factors may be of the same relative significance and some may be secondary

87 when modelling at the meso-scale (e.g., the existence of small surface

88 irregularities). Previous studies suggest that sediment input to the dune is

89 primarily controlled by trade-offs between the angle of wind approach, fetch

90 lengths, event duration and surficial moisture content (Bauer and Davidson-

91 Arnott, 2003 and Delgado-Fernandez and Davidson-Arnott, 2011), with these

92 being more or less relevant depending on the type of wind event. Strong 
93 alongshore winds, for example, may generate significant amounts of transport,

94 even with large amounts of superficial moisture content, due to long fetch

95 distances. However, as a strong wind shifts onshore at some angle, the

96 probability of generating sediment movement decreases because the combined

97 effect of surface moisture and short fetch distances can shut down the transport

98 system (Delgado-Fernandez and Davidson-Arnott, 2011). A strong onshore wind

99 may even result in wave scarping of the dune instead of aeolian sediment input

100 from the beach because of storm surge and wave run-up; these, in turn, are

101 dependent on beach width, wind speed and wind direction. Beach width varies

102 with beach slope, tidal range, and wave characteristics, whilst wind direction is of

103 essential importance both in regulating fetch distances and wave run-up

104 (Nordstrom and Jackson, 1993, Christiansen and Davidson-Arnott, 2004, Bauer

105 et al., 2009 and Delgado-Fernandez and Davidson-Arnott, 2011).

106 Nearshore processes and foredune scarping (Psuty, 1988a, Psuty,

107 1988b, Sherman and Bauer, 1993 and Hesp, 2002) and trade-offs between fetch

108 distances and angle of wind approach (Bauer and Davidson-Arnott, 2003) have

109 been incorporated into conceptual models of beach and dune interaction, but not

110 yet into numerical modelling of aeolian sand transport to coastal dunes (Bauer

111 and Sherman, 1999). There is a need to improve the state of sediment transport

112 predictions at the meso-scale both by exploring new data sets of wind

113 characteristics, supply-limiting factors and fetch distances, and by investigating

114 more comprehensive ways to input data from meteorological stations into

115 available formulae. 
116 This paper makes use of a data base of hourly measurements of winds and sand

117 deposition over months at Greenwich Dunes to develop a modelling approach for

118 resolving aeolian transport to coastal dunes on the meso (time)scale. The first

119 part of the paper introduces the conceptual model (Section 4). This combines

120 information about the nature of aeolian transport events (Delgado-Fernandez and

121 Davidson-Arnott, 2011) and elements of the framework described by Bauer and

122 Davidson-Arnott (2003), which allows parameterization of the fetch and cosine

123 effects. The essential aspect of the modelling approach is that predictions of the

124 rate of aeolian sediment transport, based first on wind speed and direction, can

125 be improved by incorporating relationships between wind, fetch, beach width,

126 and transport-limiting factors such as moisture content and snow cover. The

127 second part of the paper evaluates the viability of the approach using a simple

128 analytical procedure that allows calculation of sand transport from the time series

129 recorded at Greenwich (5 and 6). Results are compared with actual measured

130 net deposition at the foredune over the nine month study period and with

131 predictions based solely on wind speed and direction (Section 7). The discussion

132 (Section 8) focuses on areas of further research, limitations to obtain appropriate

133 observations of sediment deposition that can be compared with meso-scale

134 predictions, and alternative ways (such as probabilistic models) of translating the

135 conceptual ideas presented here into better predictions of sediment input to

136 coastal dunes. The purpose of the modelling approach is similar to that of

137 previous studies such as Fryberger and Dean, 1979 and Davidson-Arnott and

138 Law, 1990, and it is specifically designed to make use of available data from 
139 meteorological stations and/or data that can be measured simply and quickly in

140 the field since this is the only realistic approach (to date) for predicting sediment

141 supply to foredunes on a meso-(time)scale basis. Although the choice of a

142 particular sand transport equation may result in transport rates that differ over an

143 order of magnitude (Sherman et al., 1998) the focus here lies in the way to apply

144 available formulae at the meso scale.

\section{2. Regional setting}

148 This research focused on a $1.5 \mathrm{~km}$-long section of a beach-dune system at

149 Greenwich Dunes, Prince Edward Island (PEI) National Park, Canada (Fig. 1A).

150 The study area is microtidal and has a relatively narrow beach (30-40 m wide)

151 consisting predominantly of quartz sand with a mean diameter of $0.26 \mathrm{~mm}$. The

152 foredune ranges in height from 6 to $10 \mathrm{~m}$ and presents a steep stoss slope of

$15320-25^{\circ}$. The dune crest is aligned from 250 to $270^{\circ}$ and the foredune is covered

154 by marram grass (Amophila breviligulata), which exhibits considerable seasonal

155 variations in height and density. Summer months are usually characterised by

156 the development of an embryo dune, which is removed or strongly eroded during

157 winter storms every two or three years.

158 Annual average precipitation is approximately $1000 \mathrm{~mm}$, with peaks from

159 October to January due to more frequent and intense storms. Snow days (from

160 November to April) account for $30 \%$ of days with precipitation. Ice surrounding

161 PEl from January to early April forces a continental climate and strongly affects 
162 temperatures at Greenwich (which may reach $-18^{\circ} \mathrm{C}$ ). Prevailing winds from the

163 SW and W (offshore) occur predominantly in summer and are largely unable to

164 transport sediment to the foredune despite their higher frequency (Walker et al.,

165 2006). Dominant storm winds from the NE to the NW in the winter can exceed

$166100 \mathrm{~km} \mathrm{~h}^{-1}$ on occasions. These have a larger potential to deliver sediment to

167 the dune but are often associated with storm surges and heavy rain or snow.

168 Further information of the study site may be found in Walker et al., 2003, Hesp et

169 al., 2005, Davidson-Arnott et al., 2008, Bauer et al., 2009 and Darke et al., 2009.

\section{3. Field measurements and data base development}

173 3.1. Wind characteristics, fetch distances and supply limiting factors

174 The results presented in this paper cover 9 months of data collection (September

175 2007-May 2008). The experimental set-up is described in detail in Delgado-

176 Fernandez et al. (2009) and consisted of a camera system coupled with auxiliary

177 instrumentation to measure winds and transport processes (Fig. 1B). The camera

178 system was comprised of three Cannon 8-megapixel digital single lens reflex

179 (SLR) cameras controlled by a Mumford Time Machine ${ }^{\mathrm{TM}}$ programmed to take

180 simultaneous exposures every hour. The cameras were attached to a $6 \mathrm{~m}$-high

181 mast located on top of the $8 \mathrm{~m}$ foredune crest. The set-up was completed with a

182 2-Dimensional Windsonic anemometer on top of the mast at an elevation of $14 \mathrm{~m}$

183 above the beach surface. Wind speed and direction were sampled at a frequency

184 of $1 \mathrm{~Hz}$, with mean values being stored every 2 min on a HOBO Energy Pro data 
185 logger. The east-facing camera provided qualitative data on weather and wave

186 conditions over an area of approximately $1.5 \mathrm{~km}$ alongshore. The offshore and

187 west-facing cameras covered distances of $40 \mathrm{~m}$ and $100 \mathrm{~m}$ alongshore,

188 respectively. The images from these two cameras were rectified based on a

189 model developed using 40-50 ground control points (Fig. 2C), and used to

190 generate maps of fetch distances, moisture and supply-limiting factors

191 (Section 3.3).

192

193 3.2. Measurements of sand deposition

194 Measuring aeolian sediment transport over weeks to months is a challenging

195 task. The use of sediment traps at Greenwich was not feasible simply because

196 traps need to be emptied on a regular basis, including trench traps (e.g., Lynch et

197 al., 2008). Traps also present a tendency to clog when the sand is wet and it may

198 be difficult to establish their efficiency (Davidson-Arnott and Law, 1990). Two

199 Safire saltation probes (Baas, 2004) were deployed at the back beach and

200 foredune toe (Fig. 2C-D) within the field of view of the cameras. This allowed

201 assessment of the quality of Safire records by monitoring the height of the

202 piezoelectric sensor with respect to the sand surface. This height was reset to

$2035 \mathrm{~cm}$ during site visits of every 2 months but the instruments were sometimes

204 buried or even destroyed and/or removed by nearshore processes (Delgado-

205 Fernandez and Davidson-Arnott, 2011). Although there were transport events

206 over which Safires provided good measurements of saltation intensity (e.g., the 
207 storm described inSection 7.3) the time series were not continuous and thus not

208 appropriate for the purpose of long-term analysis.

209 In the absence of other techniques to measure sediment transport rates over

210 weeks directly (to the knowledge of the author), the approach taken at Greenwich

211 consisted on using the volume of sediment deposition on the dune as an indirect

212 measure of sediment transport from the beach. This was based on the work

213 by Davidson-Arnott and Law, 1990 and Davidson-Arnott and Law, 1996 who

214 assumed that, if the vegetation is high and dense, windblown sediment from the

215 beach deposits within a few tens of metres of the vegetation line. Changes in bed

216 elevation were measured using three techniques with different temporal

217 resolutions (Fig. 2C-D), with the objective of obtaining a range of values of

218 measured deposition that, though crude, were adequate to test the validity of the

219 modelling approach. First, two profiles, located on either side of the camera

220 tower and spaced $23 \mathrm{~m}$ apart, were surveyed using a Differential Global Position

221 System (DGPS) in May 2007 and June 2008. These provided information on

222 foredune topography before and after the study period. Second, bedframe posts

223 spaced approximately $3 \mathrm{~m}$ apart were established along each profile from the

224 embryo dune to the foredune crest, and were surveyed every 2 months. The

225 bedframe enables measurements that do not interfere with the dynamics of

226 vegetation and provides data on surface elevation change at 12 points within a

$2271 \mathrm{~m}$ square at each bedframe post (Ollerhead et al., 2003; Fig. 2A). Following the

228 procedure described by Law (1989) a grid was established so a particular

229 bedframe post represented a specific area of the dune with an alongshore 
230 distance of $23 \mathrm{~m}$ per $3 \mathrm{~m}$ of shore-normal dune profile (Fig. 2D). The bedframe

231 technique was designed such that each bedframe lines would encompass the

232 landward extent of aeolian transport in the vegetated dune (Davidson-Arnott and

233 Law, 1990 and Davidson-Arnott and Law, 1996). Thus, whilst an individual

234 bedframe may show wind erosion, there is no loss to the calculation of net

235 deposition across the profile because deposition is recorded in the landward

236 stations. It was assumed here that offshore aeolian transport from the embryo

237 dune was small and could be neglected. Other sources of sediment loss such as

238 sediment by-passing or wave erosion are discussed in Section 7.3. Finally, a

239 total of 4 Erosion-Deposition (ED) pins were deployed on the embryo dune and

240 back-beach. ED pins are permanent rods marked at regular intervals of $2 \mathrm{~cm}$

241 (Fig. 2B) that are located within the field of view of the cameras. Hourly changes

242 in surface elevation at each ED pin location could be measured with a precision

243 of $1 \mathrm{~cm}$ by zooming on the RGB images. This permits a much higher temporal

244 resolution compared to topographic surveys or bedframe measurements.

246 3.3. Data processing and data base development

247 Detailed information on data processing and geodatabase development may be

248 found inDelgado-Fernandez and Davidson-Arnott (2011). Measurements of sand

249 deposition and wind speed and direction were processed using standard

250 procedures and available software such as Excel and SigmaPlot. The information

251 from the camera system was processed with ArcGIS 9.2 and PCI Geomatica 9.1, 252 and followed several steps to extract numerical information such as moisture 
253 maps, shoreline position, fetch distances, vegetation density, and ice-snow

254 cover. Moisture maps were created using calibration curves that transform pixel

255 brightness into moisture content at the beach surface (Delgado-Fernandez et al.,

256 2009). The percentage of ice and snow cover was estimated from both the

257 rectified images and the unrectified images of the east camera, and classified

258 into 5 classes with increments of $20 \%$ which range from $0-20 \%$ of snow cover

259 (first class) to $80-100 \%$ of snow cover (last class). Vegetation density raster

260 datasets were extracted using unsupervised classifications with the Image

261 Analysis extension from Leica Systems. The shoreline position was digitised in

262 ArcMap and stored as feature time series, and beach width was obtained from

263 shoreline position and vegetation extent. Fetch distances were calculated from

264 beach width and wind direction.

265 Because of the need to integrate spatial and time-series data, a geodatabase

266 (PEI GDB) was built with ArcCatalog 9.2 to store the information. The PEI GDB

267 uses four types of time series data: 1) time series tables, which contain time and

268 value attributes for a given type of observation (e.g., hourly percentage of snow

269 and ice); 2) attribute series, which store temporal data for a given type of

270 observation associated with a particular location (e.g., wind speed at $14 \mathrm{~m}$ above

271 the beach recorded by the anemometer); 3) feature series, which represent

272 sequences of records in which the feature shape varies over time (e.g.; shoreline

273 position), and; 4) raster series, or time series of raster data in which each raster

274 is a snapshot in time (e.g., moisture maps). The PEI GDB manages relations

275 between different factors, permits multiple querying and allows transition 
276 between the spatial and the temporal domains using temporal geoprocessing

277 techniques.

278

\section{4. Conceptual model}

280

281 4.1. Background

282 A wind event may be simply defined from the point in time when the wind speed

283 exceeds a threshold value for sand movement to the moment when the wind

284 decreases to a value below the threshold. Potential transport for any wind event

285 may be calculated from wind speed and direction using standard equations

286 (e.g., Hsu, 1974 and Fryberger and Dean, 1979). Analysis carried out

287 by Delgado-Fernandez and Davidson-Arnott (2011) using a nine month time

288 series of wind, transport processes and supply-limiting factors at Greenwich

289 suggested three possible scenarios:

290 1. Wind events may produce no actual transport into the dune for part or all

291 of the duration of the event because the wind angle may be alongshore or

292 offshore, or because entrainment of sand from the surface is inhibited by

293 the presence of snow and ice, short fetch distances, or relatively high

$294 \quad$ surface moisture content.

2952 2. Wind events may produce sand movement to the dunes but the

296 magnitude of transport is much less than the potential transport predicted

297 by equations based on wind speed alone because the rate of sand supply

298 from the surface is reduced as a result of the effects of supply-limiting 
factors such as moisture, or because the available fetch $(F)$ is less than the critical fetch (Fc).

3. Transport into the dunes may be of the same order as the potential transport because there are no supply-limiting conditions (e.g., the existence of a wide beach, dry sand and winds with an onshore

305

4.2. Modelling assumptions

307 The goal of the modelling proposed here is to improve prediction of sediment

308 input to the foredunes at the meso scale (i.e., over a period of months) by

309 recognising the role of a few key factors and their synergistic behaviour within a

310 space that is geometrically constrained. According to Bauer and Sherman

311 (1999), reductionist studies often follow a procedure that consists on an initial

312 simplification of transport as a function of wind. The hope is that subsequent

313 modifications of the equations in order to account for complexities found at a

314 given surface will produce better explanations of the system behaviour. However,

315 even if factors such as moisture (for example) are appropriately introduced in

316 increasingly complex equations, there is no guarantee that these will improve

317 predictions. A wind well above the threshold of moist sand may produce no

318 transport as a result of other key aspects that control sediment movement such

319 as fetch distance or the influence of water levels and wave run-up

320 (e.g., Nordstrom and Jackson, 1993, Jackson and Nordstrom, 1997, Christiansen 
321 and Davidson-Arnott, 2004, Bauer et al., 2009 and Delgado-Fernandez and

322 Davidson-Arnott, 2011).

323 The main assumption adopted in this study is that sediment transport at the

324 meso scale could be better predicted based on an initial comprehensive

325 combination of key parameters. Simplifications may be introduced in the manner

326 in which this combination is modelled rather than focusing on individual factors.

327 The PEI GDB provides the input data at a level that permits testing of the

328 modelling approach in some detail, and assessment of the relative improvement

329 over calculations of potential transport rates based on wind speed alone.

330 Foredune morphological evolution has been a subject of conceptual or

331 descriptive studies (Hesp, 1988a, Hesp, 1988b, Psuty, 1988a, Sherman and

332 Bauer, 1993 and Hesp, 2002) but it is difficult to model numerically and is beyond

333 the scope of this study. The focus here lies on the prediction of sediment input to

334 the foredune which, combined with sediment output, will dictate whether the dune

335 will grow or erode (Psuty, 1988b). The area a few metres in front of the foredune

336 is particularly complex in terms of the wind flow and is often characterised by flow

337 steering and stagnation (Hesp et al., 2005 and Walker et al., 2006). When an

338 embryo dune is present in this zone, the embryo dune vegetation retards

339 sediment transport, and there is a complex relationship between the sand

340 accumulated within this vegetation and the sand that is actually transported to

341 and up the dune slope. Much of the sand deposited within the embryo dune may

342 never reach the dune slope because of erosion by waves (e.g., Christiansen and

343 Davidson-Arnott, 2004). The model presented here calculates sediment output 
344 from the beach and predicts the mass of sand crossing the "blue line" in Fig. 3A-

345 B. This study does not deal with how sediment is distributed over the dune or

346 with the resulting dune morphologies, which are affected by processes not

347 considered here (e.g., interaction of wind and topography, wave scarping,

348 vegetation patterns). Fig. 3B shows a schematic representation of a beach-dune

349 system, and includes the output area in front of the embryo dune as explained

350 above. According to Bauer and Davidson-Arnott (2003) sediment transport rates

351 may be predicted using Bagnold-type equations when the available fetch $(F)$ is

352 equal to or larger than the critical fetch $(\mathrm{Fc})$ but calculations should account for

353 the reduction in transport due to the fetch effect when $F<F c$ (see Section 6.2).

354 The red band on the beach surface (Fig. 3B) indicates the distance at which

355 transport is fully developed for a given wind speed ( $F=F c)$ and thus separates

356 the zone where the fetch effect should be considered from that where it does not

357 apply.

359 4.3. Modelling approach

360 The modelling approach consists of two steps (Fig. 4): 1) filtering of the time

361 series; and 2) calculation of transport for individual events.

363 4.3.1. Filtering

364 Filtering removes periods when transport toward the dune cannot occur because

365 wind speed is below the threshold for dry sand or wind direction is offshore. It

366 also removes those times when the magnitude of supply limiting factors such as 
367 moisture, snow and ice, and fetch length exceed a threshold above which there

368 is no potential for sand entrainment by the wind. In doing so, the filtering isolates

369 potential transport periods (PTPs) and provides information on the frequency and

370 duration of such events.

372 4.3.2. Calculation of transport for individual PTPs

373 The filtering simplifies the time series and reduces the volume of information to

374 analyse. This allows concentrating on the details of particular PTPs, such as the

375 spatial pattern of factors at an hourly scale (e.g., maps of moisture content).

376 PTPs may be characterised by different levels of complexity depending on the

377 dynamics of a few key controlling variables, namely wind speed and direction,

378 fetch distance (and thus beach width), and superficial moisture content. This

379 paper proposes the following classification of PTPs:

380

381 Type A: dry conditions—no restriction

382 PTPs may occur during onshore or oblique winds blowing over a relatively wide

383 beach with a dry surface (Fig. 5A). The saltation system is allowed to develop

384 fully for the incoming wind speed (fetch is not important) and thus transport may

385 be calculated at the output area using Bagnold-type equations and modified by

386 the cosine of wind angle following the procedure suggested by Bauer and

387 Davidson-Arnott (2003). On narrow beaches this type of event will only occur

388 under low wind speeds (short critical fetches). For wide beaches the range of

389 wind speeds involved in Type A transport will likely increase. 
391 Type B: dry conditions — restricted

392 PTPs may consist of medium complexity transport periods resulting from

393 changes in the position of the area where $F=F c$ due to varying wind speeds

394 and/or direction. Bagnold-type equations may be applied at an hourly basis

395 when $F \geq F c$, whilst transport is reduced due to the fetch effect when $F<F c$ (i.e.,

396 when the red band is landward of the output area in Fig. 5B). This type of PTP

397 may follow two general patterns:

398 B1 - Time-varying wind speed restrictions; wind direction (and thus fetch

399 length, F) may be relatively steady, but wind speed fluctuates so that there are

400 periods of time where $\mathrm{F}<\mathrm{Fc}\left(\mathrm{t}_{2}\right)$.

401 B2 - Time-varying, wind direction restrictions; changes in wind direction over

402 strong wind events may introduce complexities associated with available fetch

403 distances. On a narrow beach a strong wind may only fully develop saltation with

404 highly oblique wind angles $\left(t_{1}-t_{3}\right)$ with transport being limited when the wind

405 direction is close to shore perpendicular because $F<F c\left(t_{2}\right)$.

407 Type C: moist conditions

408 Transport often develops under very complex conditions with changes in wind

409 speed, direction, fetch lengths and moisture. The saltating system during Type C

410 PTPs is rarely fully developed because moisture limits entrainment and interacts

411 with the fetch effect in ways that are still not fully understood (Delgado-

412 Fernandez, 2010). Davidson-Arnott et al. (2008) suggest that the curve relating 
413 transport rate with fetch distance over a moist surface may be similar to that over

414 a dry surface, only with a longer critical fetch "adjusted" to wet conditions. In

415 other words, it is likely that the proportion of time during which the red band

416 in Fig. 5C is landward from the output area will increase, thus reducing transport

417 rates at the top of the beach. PTPs Type C may be divided into two general

418 categories:

419 C1 - Uniform moisture restrictions: moisture content is included via an increase of

420 the calculated Fc for an incident wind speed (Section 6.2). Moisture interacts in

421 complex ways both with the sediment transport threshold and the mass flux on

422 beach surfaces. The maximum sediment flux for dry sand as predicted by

423 transport equations (e.g., Bagnold, 1941 and Hsu, 1974) may be lower than that

424 for moist sand, similar or even higher if sediment moves across a moist, harder

425 surface ( McKenna Neuman and Maljaars Scott, 1998 and Davidson-Arnott et al.,

426 2008). However, there seems to be enough evidence suggesting that the critical

427 fetch increases with increasing beach surface moisture (Delgado-Fernandez, 428 2010).

429 C2 - Spatially complex moisture restrictions ("patch"): areas with large amounts

430 of moisture content may be considered sinks rather than source zones. The fetch

431 length can be thus measured as the distance between moisture patches and the

432 output area, that is, moisture zones reduce the actual space for transport to

433 develop. The data set obtained at Greenwich contains several onshore transport

434 periods where the foreshore area became progressively wetter as a thin layer of

435 sediment was removed by wind gusts whilst the back-beach became 
436 progressively drier because of accumulation of dry sand. This resulted in a

437 decrease of the fetch distance over time. The approach taken here oversimplifies

438 the dynamics of events of type C2 but incorporates hourly variations of fetch

439 distances.

\section{5. Description of the data set}

443 The input data for the model consisted of hourly values of wind speed and

444 direction (obtained from 2 min records from the Windsonic on top of the

445 mast; Section 3.1), beach width, snow and ice cover, fetch distances and

446 moisture content. The PEI GDB contains detailed information on the spatial

447 distribution of some of these factors for every given image (e.g., shoreline

448 position) (Section 3.1) but for the purpose of this paper only hourly averages

449 were considered.

450 Moisture maps were stored at a $0.05 \mathrm{~m}$ grid resolution within the PEI GDB. The

451 mean hourly value was obtained by considering an area of $10 \mathrm{~m}$ in front of the

452 embryo dune. This area was usually out of the tidal influence and wide enough to

453 obtain representative mean values of moisture content due to rain fall, snow melt,

454 or large wave swash. The mean value for moisture $(\mu)$ was then classified into

455 three categories: 1) "dry": $\mu \leq 2 \%$; 2 "medium": $2 \%<\mu<10 \%$; and; 3 ) "wet":

$456 \mu \geq 10 \%$. The objective of this classification was to broadly differentiate periods of

457 time when moisture is not likely to play a major role ("dry") from moments when

458 moisture completely prevents transport ("wet") (Davidson-Arnott et al., 2008). 
459 The "medium" class comprises all cases (the majority) when complex interactions

460 between wind thresholds and rapid drying of superficial sediments are expected

461 (Wiggs et al., 2004 and Davidson-Arnott and Bauer, 2009).

462 Snow-ice cover was averaged from measurements obtained from three

463 simultaneous images taken from the cameras. Delgado-Fernandez and

464 Davidson-Arnott (2011)observed that transport was completely shut down at

465 Greenwich when half or more of the beach was covered by ice-snow.

466 Complications associated with modelling aeolian sand transport in the presence

467 of snow are beyond the scope of this paper and thus only the threshold

468 associated with ice-snow presence is used here in the filtering stage

469 (Section 6.1). Beach width was obtained from mean values of shoreline position

470 and vegetation extent for the offshore and west-facing cameras. The available

471 fetch distance $(F)$ was then calculated considering the relation between beach

472 width (W) and the angle of wind approach from shore perpendicular $(\alpha)$ using the

473 following expression:

474

$$
F={ }^{w} / \cos \alpha
$$

Equation(1)

476 Finally, the majority of night exposures were enhanced as described by Delgado-

477 Fernandez et al. (2009) which allowed extraction of the variables mentioned

478 above. There were only a few very dark night shots when measurements were

479 not possible and thus mean values were interpolated based on conditions during

480 the last exposure in the evening and the first exposure the following morning and 
481 on predicted tidal elevation. This introduced a small level of uncertainty but

482 resulted in a data set of synchronised mean hourly values of wind speed and

483 direction, snow-ice cover, beach width, fetch distances, and moisture content that

484 could be used for modelling purposes.

\section{6. Analytical procedure}

488 Section 8 discusses possible alternatives to develop numerical models based on

489 the approach described in Section 4. Only a simple analytical procedure was

490 conducted here to test whether calculations of sediment input to coastal dunes

491 based on deterministic formulae (e.g., Hsu, 1974, Fryberger and Dean,

4921979 and Davidson-Arnott and Law, 1996) may be improved using the modelling 493 approach.

495 6.1. Filtering the time series

496 The numerical values for the thresholds used for isolating PTPs were based on

497 the work of Delgado-Fernandez and Davidson-Arnott (2011). These authors

498 observed that no significant sediment input to the dunes occurred at Greenwich

499 under any of the following conditions: wind speed $(U)<6 \mathrm{~m} \mathrm{~s}^{-1}$; offshore wind

500 direction; "wet" surfaces $(\mu \geq 10 \%)$; snow and ice cover $>50 \%$; and beach

501 inundation by nearshore processes. This is the combination of all thresholds is a

502 necessary condition for the potential existence of transport: 


$$
\begin{aligned}
& U>6 \mathrm{~ms}^{-1} \\
& \text { onshore component } \\
& \text { if } \rightarrow \quad \mu<10 \% \quad \rightarrow \text { PTP } \\
& W>0 \mathrm{~m} \\
& \text { snow and ice }<50 \%
\end{aligned}
$$

505 Whilst any one of these thresholds will inhibit transport, the PTPs isolated by this

506 procedure may not all include periods of actual transport (Section 8). The filtering

507 technique, however, narrows down potential transport events whilst preventing

508 the loss of data. Importantly, and because of the inclusion of beach width (and

509 therefore fetch distance) as a necessary condition for transport to develop, the

510 filtering eliminates from the time series those periods where storms with strong

511 onshore winds produce storm surge and wave run up that inundates the beach.

513 6.2. Calculating transport for individual PTPs

514 A key aspect of the conceptual model is the importance of considering other

515 factors in addition to wind speed and direction. The choice of a particular formula

516 for predicting sediment transport is important for calculating absolute values of

517 sediment output from the beach, but establishing the suitability of a particular

518 equation over another is beyond the scope of this paper. For detailed reviews

519 about instantaneous transport equations see Horikawa et al., 1986, Nickling,

5201994 and Sherman et al., 1998. The focus here was to assess the performance

521 of the two modelling steps and for this purpose any relatively simple expression

522 relating wind speed and sediment transport rate was sufficient. The empirical

523 equation proposed by Hsu (1974) was selected here simply because it relates 
524 transport directly with wind velocity rather than with shear velocity. Estimations of

525 shear velocity require measurements of velocity profiles or detailed knowledge of

526 the roughness length ( $\left.z_{0}\right)$ and internal boundary layer development, which

527 changes considerably spatially and temporally (Davidson-Arnott and Law, 1996).

528 Whilst it would have been possible to estimate shear stress from assumptions of

529 surface roughness this was likely to be a constant in this study and therefore

530 would have had no impact to improve the modelling. Hsu's formula introduces a

531 degree of uncertainty because Hsu adjusted the constant to the particular

532 beaches he worked on. However, it is based on a previous version using shear

533 velocity (Hsu, 1973) which predicts sediment transport rates close to those

534 calculated by Bagnold's (1941) model and that are in the middle range compared

535 to a number of models tested by Sherman et al. (1998). Hsu's equation was also

536 adopted in a similar type of study by Davidson-Arnott and Law (1996), who

537 included the cosine effect for its use when wind speed and direction are the only

538 data available. According to these authors, the potential transport rate into the

539 dunes per unit alongshore distance ( $\mathrm{qn}, \mathrm{kg} \mathrm{m}^{-1} \mathrm{~s}^{-1}$ ) may be expressed as:

$541 \mathrm{q}_{\mathrm{n}}=1.16 \times \times^{10-5} \times \mathrm{U}^{3} \cos \alpha \quad$ equation (2)

543 where $\mathrm{U}$ is hourly wind speed in $\mathrm{m} \mathrm{s}^{-1}$. Thus qn is the predicted rate of sediment

544 movement at the output area (Fig. 5A) based on wind speed and direction alone,

545 and hence only applicable in type A PTPs (no restrictions), or during $\mathrm{t} 1$ and $\mathrm{t} 3$ in

546 type B PTPs. 
547 Despite advances in the modelling of the fetch effect in agricultural areas

548 (e.g., Stout, 1990, Gillette et al., 1996 and Fryrear et al., 2000) there is no

549 accepted equation describing the increase of sediment transport rate with fetch

550 distance on beaches (Delgado-Fernandez, 2010). This poses major difficulties

551 when trying to incorporate the fetch effect into the modelling of aeolian sediment

552 input to the foredunes, especially with strong winds associated with long critical

553 fetch distances (Davidson-Arnott and Law, 1990, Spies and McEwan,

5542000 and Dong et al., 2004) (during t2 in PTPs type B). Bauer and Davidson-

555 Arnott (2003) proposed four harmonic functions to describe the increase of

556 sediment transport with distance. According to Delgado-Fernandez (2010), their

557 Equation 2a is consistent with other empirical equations in agricultural areas and 558 thus it is used in here:

559

$$
q_{n}(F)=q_{n} \sin \left(\frac{\pi}{2} \frac{F}{F_{c}}\right)
$$

561 Eq. (3) needs numerical values for Fc but there are no current methods to

562 calculate this (Delgado-Fernandez, 2010). There is, however, some supporting

563 evidence suggesting that it is reasonable to estimate Fc given a particular wind

564 speed blowing over a dry surface. Fig. 6 shows a high correlation between wind

565 speed and the distance where transport attains a maximum as reported in the

566 numerical simulations by Spies and McEwan (2000) (curve A) and field results

567 by Davidson-Arnott and Law (1990) (curve B). Curve B has a steeper slope in 
568 agreement with other studies in natural areas showing critical fetch distances that

569 are longer than those found by numerical simulations or laboratory analysis

570 (e.g., Gillette et al., 1996, Fryrear et al., 2000 and Davidson-Arnott et al., 2008).

571 The expression associated with curve B is used here:

572

$573 \quad F_{c}=4.38 \times U-8.23$

Equation (4)

574

575 This permits the generation of a set of $\mathrm{Fc}$ for a relevant range of wind speeds (U)

576 and testing of the modelling approach. No claim is made here regarding the

577 general applicability of Eq. (4) beyond this analytical procedure.

578 Whilst the filtering deals with "wet" periods and Eqs. (2) and (3) are used for "dry"

579 PTPs type A and B (respectively) there is a need to include "medium"

$580(2 \%>\mu>10 \%)$ moisture content values characteristic of PTPs type C. There are

581 several equations relating the threshold of sand movement with moisture content

582 (e.g., Belly, 1964, Logie, 1982 and McKenna Neuman and Nickling, 1989) or with

583 sediment transport rates (e.g.,Hotta et al., 1984 and Sarre, 1987) but none on the

584 relation between moisture and critical fetch distances (Delgado-Fernandez,

585 2010). Ideally this research would benefit from studies targeting aeolian sediment

586 transport during PTPs Type C, the most common situation at the meso scale

587 (Delgado-Fernandez and Davidson-Arnott, 2011). In the absence of tools to

588 model the complex interactions between moisture, fetch, and wind

589 characteristics, the following procedure was adopted. 1) Based on observations

590 byDavidson-Arnott et al. (2008) it was assumed that homogenous moisture 
591 content (PTPs Type C1) increased the critical fetch calculated for dry sand (Fc)

592 to a new larger value $(F c \mu)$ for a given wind speed with the increase being

593 proportional to the value for moisture content. On this basis, a simple arbitrary

594 scheme was utilised, with $\mathrm{Fc} \mu$ resulting from an increase of $\mathrm{Fc}$ by $50 \%$ when

$5954 \% \leq \mu<6 \%$, and by $75 \%$ when $6 \% \leq \mu<10 \%$. For $2 \% \leq \mu<4 \%$ it was assumed

596 that the surface was likely subject to rapid drying and stripping of sand grains by

597 wind gusts (Wiggs et al., 2004) and Fc was not modified. 2) When clear

598 "patches" of moisture vs. dry zones were present at the beach surface, Fcwas

599 calculated for dry sand but the available fetch $(F)$ was measured from the

600 landward limit of damp areas. Again, it is acknowledged here that this is an over-

601 simplified procedure adopted to permit operationalization of the model in the

602 absence of an adequate technique based on field and/or laboratory data.

603 Fig. 7 shows a diagram of the analytical procedure. The steps may be

604 programmed with any scripting language such as Python or even conducted with

605 Excel. For a given hour in a selected PTP the model calculates Fc based on wind

606 speed using Eq. (4), checks the mean moisture content, and obtains (if

607 applicable) $F_{c} \mu$. If $F_{c}$ (or $F c \mu$ ) $\leq F$ (red band in Fig. 5is seaward from the output

608 area) then the model applies Eq. (2). If $F_{c}($ or $F(\mu)>F$ the model applies Eq. (3).

609 Finally, the procedure calculates the total amount of transport for a particular

610 PTP (QPTP) by adding hourly values of sand transport rates:

611

$$
Q_{P T P}=\sum_{q=1}^{q=n} q_{n}
$$




\section{7. Modelling approach results and testing}

615 The modelling approach predicts a total amount of sand crossing the output area

616 over any period of time longer than $1 \mathrm{~h}$. To compare this amount with actual

617 deposition at the dune the assumption is that the embryo dune and foredune trap

618 everything that is delivered to them over the time period considered. There are

619 several uncertainties associated with this. First, survey methods or bedframe

620 posts record net deposition, and thus do not reflect potential periods of erosion.

621 Second, sediment by-passing and being transported over the dune crest and

622 beyond is not measured by the techniques used in this study. These limitations

623 are discussed in the following sections.

625 7.1. Measured deposition over 9 months

626 Fig. 8 shows the results of both topographic profiles $(A)$ and bedframe

627 measurements (B). Net changes from May 2007 to June 2008 were minimal and

628 concentrated at the lower sections of the foredune (lower slope and dune toe)

629 and embryo dune. Bedframe posts landward of the foredune crest (1-3 W)

630 showed no substantial changes over the study period. The largest net deposition

631 occurred from October to December 2007, which was probably related to a single

632 very strong transport event on November 9-13 (Section 7.3). Table 1 shows

633 values of erosion and deposition recorded by each of the bedframe posts (BP).

634 The mean net change over the dune stoss slope (bedframe posts seaward from 
635 the crest, cross-shore distance $=18 \mathrm{~m}$ ) was $9.2 \mathrm{~cm}$ on Line $\mathrm{E}$ and $6.9 \mathrm{~cm}$ on line

$636 \mathrm{~W}$, which give an average accretion of $8.05 \mathrm{~cm}$ over 9 months.

638 Table 1. Results for bedframe posts (BP) over 9 months of data collection. Note

639 that BP1-3 in line W was not included in the calculations. Changes are expressed

640 in cm. Fig. 2 and Fig. 8 show the location of the bedframe posts.

\begin{tabular}{|c|c|c|c|c|c|c|c|c|}
\hline $\begin{array}{l}\text { Line } \\
\mathrm{E}\end{array}$ & Deposition & Erosion & $\begin{array}{l}\text { Net } \\
\text { change }\end{array}$ & Location & $\begin{array}{l}\text { Net } \\
\text { change }\end{array}$ & Erosion & Deposition & $\begin{array}{l}\text { Line } \\
\text { W }\end{array}$ \\
\hline- & & & & $\begin{array}{l}\text { Dune } \\
\text { trough }\end{array}$ & -1.94 & -2.41 & 0.47 & BP1 \\
\hline- & & & & $\begin{array}{l}\text { Dune } \\
\text { trough }\end{array}$ & 1.79 & -0.33 & 2.12 & BP2 \\
\hline- & & & & $\begin{array}{l}\text { Dune } \\
\text { trough }\end{array}$ & 0.43 & -1.45 & 1.88 & BP3 \\
\hline BP1 & 1.48 & -0.47 & 1.01 & $\begin{array}{l}\text { Dune } \\
\text { crest }\end{array}$ & -0.94 & -1 & 0.06 & BP4 \\
\hline BP2 & 3.9 & -2.64 & 1.26 & $\begin{array}{l}\text { Upper } \\
\text { slope }\end{array}$ & 1.81 & -0.28 & 2.09 & BP5 \\
\hline BP3 & 6.5 & -0.47 & 6.03 & $\begin{array}{l}\text { Upper } \\
\text { slope }\end{array}$ & & & & - \\
\hline BP4 & 20.47 & -2.83 & 17.64 & $\begin{array}{l}\text { Low } \\
\text { stoss } \\
\text { slope }\end{array}$ & & & & - \\
\hline BP5 & 20.52 & -0.28 & 20.24 & $\begin{array}{l}\text { Dune } \\
\text { toe }\end{array}$ & 13 & -4 & 17 & BP6 \\
\hline- & & & & $\begin{array}{l}\text { Embryo } \\
\text { dune }\end{array}$ & 13.95 & -0.36 & 14.31 & BP7 \\
\hline & 10.6 & -1.3 & 9.2 & Mean & 6.9 & -1.4 & 8.4 & \\
\hline
\end{tabular}

642 Davidson-Arnott and Law (1996) used the following relationship to convert values

643 of volume of sediment deposition (or erosion) to a total sediment transport (q): 


$$
d q / d x=(d h / d t) \gamma
$$

646 where $\mathrm{dh} / \mathrm{dt}$ is the change in elevation over a particular time period and $\mathrm{x}=$

647 distance along profile. A mean value for bulk density ( $\mathrm{Y}$ ) of $2082 \mathrm{~kg} \mathrm{~m}^{-3}$ was

648 obtained from sand samples at the laboratory and corresponded to that

649 estimated assuming a sediment density of $2650 \mathrm{~kg} \mathrm{~m}^{-3}$ (Bagnold, 1941) and a

650 porosity of 0.23 (Fetter, 1994). Note that for the reason noted above, the

651 bedframes landward of the dune crest (1-3 W) were not considered in the

652 calculations. The net average change over 9 months recorded by the bedframes

653 was QBF-net $=3017 \mathrm{~kg} \mathrm{~m}^{-1}\left(1.45 \mathrm{~m}^{3} \mathrm{~m}^{-1}\right)$, based on a net average accretion of

$6548.05 \mathrm{~cm}$ along the profile.

655 The values in Table 1 reflect net quantities, and thus may be missing important

656 information about sediment deposition or erosion between surveys. In fact the

657 bedframe posts recorded a few periods of erosion (or possible compaction),

658 which introduces the question of whether net changes over months

659 underestimate sand delivered by wind over shorter periods of time. If only

660 deposition is considered (average $=9.5 \mathrm{~cm}$ ) the gross amount of sand deposited

661 over the dune is increased to QBF-only_dep $=3560 \mathrm{~kg} \mathrm{~m}^{-1}\left(1.71 \mathrm{~m}^{3} \mathrm{~m}^{-1}\right)$.

662 Fig. 9 displays the ED pins hourly records during the 9 months of study period.

663 Elevation changes were quite dynamic at the back beach and embryo dune, with

664 many small erosion and deposition periods of less than $\pm 5 \mathrm{~cm}$, and several of

665 more than $\pm 10 \mathrm{~cm}$. Table 2 shows the result of summing periods of erosion and 
666 deposition, and the net changes recorded at the end of the study period by the

667 ED pins. The average net deposition at the embryo dune was $26.5 \mathrm{~cm}$. This

668 results in QED-net $=4966 \mathrm{~kg} \mathrm{~m}^{-1}\left(2.38 \mathrm{~m}^{3} \mathrm{~m}^{-1}\right)$ according to Eq. (6). The average

669 gross deposition (erosion not considered) at the embryo dune was approximately

$67083 \mathrm{~cm}$, which equates to QED-only_dep $=15552.5 \mathrm{~kg} \mathrm{~m}^{-1}\left(7.47 \mathrm{~m}^{3} \mathrm{~m}^{-1}\right)$. A

671 discussion about the significance of these differences is presented in Section 8.

673 Table 2. Results for ED pins over 9 months of data collection. Changes are

674 expressed in cm. Fig. 2 shows the location of ED pins.

\begin{tabular}{|l|l|l|l|l|}
\hline ED pin & Deposition & Erosion & Net change & Location \\
\hline 1 & 94 & -67 & 27 & Embryo dune \\
\hline 2 & 72 & -46 & 26 & Embryo dune \\
\hline 3 & 51 & -60 & -9 & Back beach \\
\hline 4 & 71 & -67 & 4 & Back beach \\
\hline Mean ED1-2 & 83 & -56.5 & 26.5 & Embryo dune \\
\hline Mean ED3-4 & 61 & -63.5 & -5 & Back beach \\
\hline
\end{tabular}

676 7.2. Sediment input predicted over 9 months

677 The analytical procedure was run using data for a nine month period

678 (6576 h). Table 3summarises the output of both the filtering (Qfiltering) and

679 calculation of transport over isolated PTPs (QPTP). Qn is the total amount of

680 sediment transport predicted using Eq. (2), which represents the quantity that

681 would be calculated using a traditional approach based solely on wind speed and

682 direction (e.g., Fryberger and Dean, 1979 and Wahid, 2008). QptP represents the

683 actual output of the analytical procedure, or transport calculated for all PTPs

684 considering supply-limiting conditions and different types of events. Results are 
685 expressed in $\mathrm{kg} \mathrm{m}^{-1}\left(\mathrm{Q}_{\mathrm{i}}\right)$, the number of hours of predicted transport and the

686 percent of time they represent over 9 months, and, most importantly, the relation

687 with measured values (Qi respect QBF-net). For consistency with previous studies

688 (e.g., Davidson-Arnott and Law, 1996) the modelling output was compared

689 against the average net change recorded by the bedframes over the entire

690 foredune (BP 1-3 W excluded). The rest of observed changes have been

691 included in Table 3 for discussion purposes (Section 8).

692

693 Table 3. Output of the modelling procedure and comparison of predicted

694 quantities with observed net deposition at the embryo dune and foredune. $Q_{n}$ :

695 total amount of sediment transport predicted using Eq. (2); Qfiltering: output of the

696 filtering step; QpTP: output of the calculation of transport over isolated PTPs; QED-

697 only_dep: average gross deposition (erosion not considered) measured by ED pins

698 at the embryo dune; QED-net: average net change measured by ED pins at the

699 embryo dune; QBF-only_dep: average gross deposition (erosion not considered)

700 measured by bedframes over the foredune; QBF-net: net average change

701 measured by bedframes over the foredune. Note that in the particular case of this

702 time series the majority of events resulting in wave run-up or storm surge (beach

703 width $>0 \mathrm{~m}$ ) were already filtered by the effects of high amounts of moisture

704 content or snow-ice cover (thus the low values associated to a few remaining 705 periods of time).

\begin{tabular}{|c|c|c|c|c|}
\hline Factor & $\begin{array}{l}\text { No. of } \\
\text { hours }\end{array}$ & $\begin{array}{l}\% \\
\text { time }\end{array}$ & $Q_{i}\left(k m^{-1}\right)$ & $\begin{array}{l}\text { Qi respect } \\
\text { QBF-net }\end{array}$ \\
\hline \multicolumn{5}{|l|}{ Predicted Q } \\
\hline$Q_{n} \quad$ Wind & 2018 & 31 & 86458 & 28.7 QBF- \\
\hline
\end{tabular}




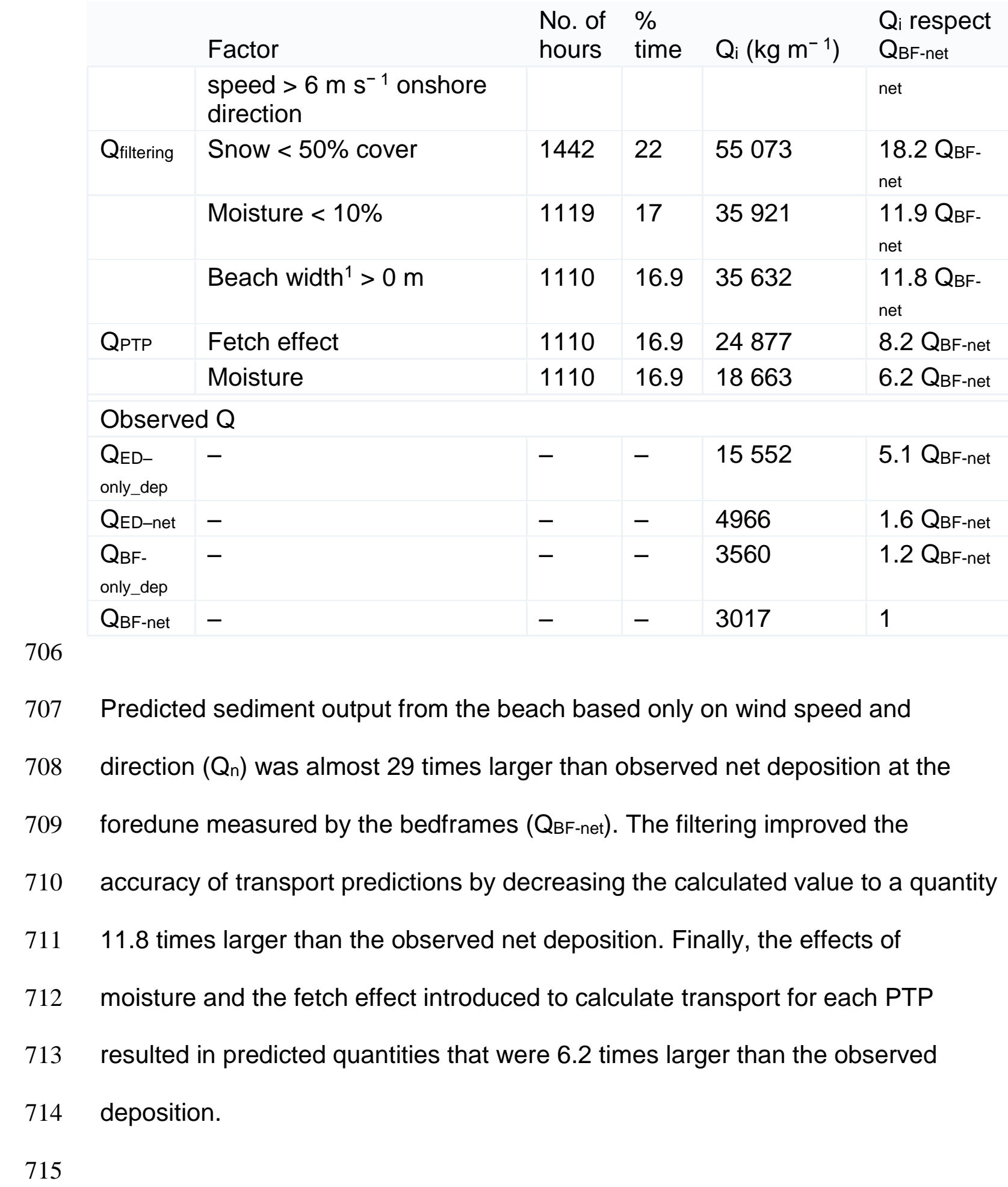


7.3. Measured deposition over a storm event

717 A storm that began on November 9, 2007, was selected as an example of the

718 performance of the modelling approach over a particular wind event because of

719 several tradeoffs between key factors, such as the cosine and the fetch effect, or

720 the influence of moisture content. This event is described in detail by Delgado-

721 Fernandez and Davidson-Arnott (2011), and is a typical example of transport

722 occurring under Type C conditions (Section 4.3.2).

723 Fig. 10 displays the time series of wind speed and direction (A), tidal elevation

724 and saltation intensity recorded by a Safire located at the back-beach (B), beach

725 width (C), and fetch distances and classified moisture content (D) (Section 5).

726 The wind started blowing over the threshold for dry sand movement at 10 am on

727 November 9 and died out at 3 am on November 13, resulting in a wind event

728 duration of $90 \mathrm{~h}$. Strong transport was observed under specific conditions on

729 November 11. Relatively low wind speeds combined with moisture content from 2

730 to $4 \%$ precluded grain entrainment on November 9 . An increase in wind speed

731 on the morning of November 10 generated limited sand transport, which fully

732 developed during the day due to a further increase in wind speed coinciding with

733 low tide and oblique angle of wind approach. A gradual change in wind direction

734 to onshore-perpendicular decreased the available fetch distance and produced

735 wave up-rush eventually resulting in the beach inundation. The peak wind

736 speeds coincided with onshore winds thus precluding sediment movement during

737 the rest of the event because of storm surge and wave run-up. 
738 The complexity of the ED pin records at the end of the storm illustrates some of

739 the points raised in the discussion (Section 8). ED pins 1 and 2 recorded net

740 deposition of 4 and $25 \mathrm{~cm}$ respectively at the embryo dune (see Fig. 2 for

741 location). ED 4 recorded $10 \mathrm{~cm}$ of net deposition at the back beach but ED 3

742 recorded $15 \mathrm{~cm}$ of erosion at the back beach. If an average deposition of $14.5 \mathrm{~cm}$

743 at the embryo dune is assumed, the total amount of sediment deposited during

744 this particular event was of $905.7 \mathrm{~kg} \mathrm{~m}^{-1}$ length of shoreline $\left(0.43 \mathrm{~m}^{3} \mathrm{~m}^{-1}\right)$. Note

745 that this does not consider sediment deposited at the dune toe and beyond

746 because of the absence of instrumentation.

748 7.4. Sediment input predicted over a storm event

749 Fig. 10E-G displays the analytical procedure output at an hourly scale.

750 Prediction of sediment output from the beach based on wind speed and direction

751 only resulted in a peak of transport rates coinciding with the peak of strong

752 onshore winds (Fig. 10E), over-predicting the amount delivered to the dune

$753\left(Q_{n}\right.$ for this event $\left.=9470 \mathrm{~kg} \mathrm{~m}^{-1}\right)$. The introduction of thresholds for moisture

754 content $(\mu<10 \%)$ and beach width $(\mathrm{W}>0 \mathrm{~m})$ as necessary conditions for

755 transport removed the majority of strong onshore winds (Fig. 10F), resulting in

756 improved predictions ( $Q$ filtering $=3720 \mathrm{~kg} \mathrm{~m}^{-1}$ ). Predicted transport was

757 QPTP $=1698 \mathrm{~kg} \mathrm{~m}^{-1}\left(0.65 \mathrm{~m}^{3} \mathrm{~m}^{-1}\right)$ after considering Fc or Fc $($ Fig. 10G), which

758 was slightly higher but on the same order of magnitude as the observed

759 deposition over the storm, thus confirming the viability of the modelling approach. 


\section{Discussion}

763 The filtering improved calculations of sediment input to the foredunes by

764 eliminating periods of time where transport was predicted based solely on wind

765 speed and direction, but where no transport occurred because of the effect of

766 one or more limiting factors. The improvement made by incorporating both the

767 fetch effect and moisture was significant and suggests that further advances in

768 modelling instantaneous relations between wind speed, fetch distances, moisture

769 content and transport over a variety of situations will aid in refining predictions.

770 The results of the analytical procedure suggest, however, several areas where

771 the two modelling steps can be further refined. The thresholds used in the

772 filtering step for this particular study were quite conservative with the result that

773 the number of PTPs identified is much greater than the 27 transport events

774 actually observed over the same time period by Delgado-Fernandez and

775 Davidson-Arnott (2011). As shown in Fig. 11, all observed transport events were

776 included within the set of predicted PTPs; i.e., no actual transport events were

777 missed. However, there were a number of predicted PTPs where no transport

778 was observed. In the majority of cases this occurred where winds were slightly

779 above the threshold for dry sand but transport did not occur because of moderate

780 levels of moisture on the beach. Transport would have occurred with either

781 stronger winds or drier sediments. In some cases transport may have been

782 inhibited by factors which could not be measured by the remote station at

783 Greenwich (e.g. topographic changes). In any case the filtering did not eliminate 
784 observed transport events from the calculations suggesting appropriate threshold

785 values at this site (i.e., no loss of data). Transport within a number of PTPs was

786 also over-predicted. In many cases this was the result of the inadequacies of the

787 modelling of transport rates associated with moderate wind speeds and

788 moderate levels of surface moisture content and/or spatially complex patterns of

789 moisture content. For example, during the first quarter of the storm described

790 in Fig. 10, low wind speeds of $\approx 10 \mathrm{~m} \mathrm{~s}^{-1}$ yielded a short $\mathrm{Fc}$ of $\approx 15-20 \mathrm{~m}$.

791 Moisture ranged from 2 to $4 \%$ due to intermittent rain and

792 thus $\mathrm{Fc} \mu=\mathrm{Fc}$. $\mathrm{F}$ oscillated from 30 to $50 \mathrm{~m}$ due to a relatively wide beach and

793 oblique angle of wind approach. BecauseFc $<\mathrm{F}$ transport was predicted with the

794 same magnitude as the rate solely based on wind speed and direction (compare

$795 \mathrm{E}$ and $\mathrm{F}$ in Fig. 10). The effect of both moisture and fetch was more visible during

796 the second quarter of the storm, when strong wind speeds and larger moisture

797 contents resulted in Fc $\mu$ F. This research will thus benefit from detailed studies

798 on the combined effect of fetch distances and moisture content at the beach,

799 because they play an important role in modifying the magnitude of calculated

800 transport for individual PTPs.

801 The substantial differences in observed deposition with different techniques

802 introduce uncertainty with respect to the appropriate ('true') value used in the

803 comparison with predicted quantities. In part this reflects inadequacies in the

804 number and placement of both bedframe stations and ED pins, and in particular

805 a failure to recognise the ease with which a large number of ED pins could have

806 been deployed. The simplicity and higher temporal resolution provided by placing 
807 the ED pins in the field of view of the cameras greatly enhances the potential of

808 the camera monitoring system for future studies of beach/dune interaction and

809 changing dune morphology. The hourly time series of the ED pins permitted

810 much better assessment of periods of erosion as well as accretion and indicated

811 that net changes measured by sampling at relatively long time intervals (e.g., bi-

812 monthly bedframe measurements) underestimate the gross amount of sand

813 delivered to the dune. All ED pins recorded several periods of sand removal due

814 both to wave and wind erosion (as observed from the cameras). This suggests

815 that some of the sediment delivered from the beach to the embryo dune was

816 never actually recorded by low temporal resolution techniques, because these

817 integrated erosion and sand removal within net deposition observations.

818 Nevertheless, they also serve to highlight the difficulty of distinguishing wave

819 erosion and deposition from wind erosion and deposition in the area of

820 overlapping influence, and the limitations associated with a few point

821 measurements within this zone.

822 Efforts to fully explore the capabilities of the time series stored in the PEI GDB

823 are currently being developed. The PEI GDB contains raster datasets and

824 feature series with information about shoreline configuration, vegetation patterns,

825 or spatial changes on moisture every hour. In particular, it is at the PTP level that

826 the complexities associated with these factors may improve the model

827 performance, especially during scenarios such as PTPs type C. However, in the

828 broader context of sand transport prediction at the meso scale, two important

829 aspects are worthy of consideration: 1) the potential benefits of adopting 
830 probabilistic approaches versus a deterministic procedure; and 2) the potential

831 for extracting estimates of key controlling variables, such as surface moisture

832 content and beach width, from data measured at standard meteorological

833 stations for the majority of situations where there is no direct monitoring of the

834 beach and dune system. Probabilistic approaches are common in weather

835 forecasting and estimate the probability of an event occurrence/magnitude based

836 on past (historical) data whilst including information on the uncertainty of the

837 prediction. However, they need historical records of several environmental

838 factors and there is a lack of long-term datasets on sediment transport processes

839 at the beach. The monitoring station at Greenwich has being collecting data for

840 over a period of 2 years so further analysis of wind, supply limiting factors, and

841 transport processes may provide a good basis for a probabilistic model.

842 Secondly, it would be worth exploring ways in which limiting factors such as

843 beach surface moisture, snow and ice and beach width could be estimated from,

844 e.g., hourly values for rainfall or snowfall, temperature, tidal range, average

845 beach width and some simple storm surge and run-up model.

846 Finally, it is worth stressing that the purpose of this work was not to provide an

847 absolute accurate prediction of sediment input to Greenwich Dunes over

8489 months (if this is possible at all) but to test the effectiveness of a modelling

849 approach that explicitly acknowledges the key role played by supply-limiting

850 factors such as moisture, fetch and vegetation in determining the actual sediment

851 supply from the beach to coastal foredunes over periods of months and years.

852 The results demonstrate that an approach based on transport-limited models is 
853 inadequate at this temporal scale and that improved accuracy in prediction will

854 come not from small refinements to traditional transport-limited models, but

855 rather from the incorporation of the supply-limiting complexities. Whilst some of

856 the variables identified at Greenwich may be irrelevant at other sites (e.g., snow-

857 ice cover), the thresholds associated with beach inundation or moisture content

858 are probably more universal and others, such as pebble lag development and

859 flotsam, may also be relevant. New time series based on the type of monitoring

860 system deployed here are, thus, desirable as they will aid in identifying particular

861 key factors regulating the frequency and magnitude of aeolian transport events at

862 other beach-dune systems and provide a rich data base which can be used to

863 generate an improved supply-limited approach to meso-scale modelling of

864 sediment supply from the beach.

866 9. Conclusions

868 The analyses presented in this paper show the potential for improved predictions

869 of sediment input to coastal dunes using a simple modelling approach

870 incorporating two steps. The first step reduces prediction of sediment supply to

871 the foredune by removing wind events that do not result in transport because of a

872 high threshold for sediment movement due to the magnitude of one or more

873 supply-limiting variables, and thus isolates periods of time (PTPs) where

874 predictive efforts should focus. The second step introduces the effect of fetch

875 distances and limiting factors such as surface moisture content, which regulate 
876 the supply of sediment from the surface and thus reduce the magnitude of

877 transport compared to that predicted by transport-limited models. The use of the

878 modelling approach greatly improves calculations of sediment supply toward the

879 dune area, and suggests that further improvements can be made through the use

880 of similar monitoring systems in other coastal dune environments. Finally the

881 results of this study show that further improvements in our ability to predict

882 sediment supply to coastal foredunes will require improvements in our ability to

883 measure sand transport from the beach and deposition in the foredune at the

884 same temporal scale.

886 Acknowledgements

888 I would like to express special gratitude to the extensive reviews and major

889 contributions by Robin Davidson-Arnott, who has provided many of the

890 conceptual and methodological tools for this project. I would also like to thank the

891 extensive feedback provided by Bernie Bauer, and his valuable ideas associated

892 with the modelling. Together these two researchers have provided the core ideas

893 of the work presented here. Bill Nickling and Ray Kostaschuck provided detailed

894 comments over earlier drafts that have greatly improved the present manuscript.

895 Special thanks are extended all the staff at Greenwich Dunes, especially Kirby

896 Tulk, Allan Doyle, Tarah McFee, Roger Steadman, and Miguel Santos. This

897 study was supported by a research grant from Prince Edward Island National

898 Park and a Natural Sciences and Engineering Research Council of Canada 
899 Discovery Grant to R. Davidson-Arnott, and by an Ontario Graduate Scholarship

900 (Ministry of Training, Canada) to I. Delgado-Fernandez. Finally, I would like to

901 thank Chris Hugenholtz and an anonymous reviewer, whose recommendations

902 have greatly improved the final version of this paper.

903

904 References

905

906 Bagnold, R.A., 1941. The physics of blown sand and desert dunes. London, $907 \quad$ Methuen, $265 \mathrm{pp}$.

908 Bauer, B.O. and Davidson-Arnott, R.G.D., 2003. A general framework for 909 modelling sediment supply to coastal dunes including wind angle, beach $910 \quad$ geometry and fetch effects. Geomorphology, 49, 89-108.

911 Bauer, B.O. and Sherman, D.J., 1999. Coastal dune dynamics: Problems and

912 Prospects. In: A.S. Goudie, I. Liivingstone and S. Stokes (Editors), Aeolian

913 Environments, Sediments and Landforms. John Wiley and Sons, pp. 71$914 \quad 104$.

915 Bauer, B.O., Davidson-Arnott, R.G.D., Hesp, P.A., Namikas, S.L., Ollerhead, J., 916 Walker, I.J., 2009. Aeolian sediment transport on a beach: Surface 917 moisture, wind fetch, and mean transport. Geomorphology, 105, 106-116

918 Belly, P., 1964. Sand movement by wind, U.S. Army Corps of Engineers CERC, $919 \quad$ Tech. Memo 1, 38. 
920 Carson, M. A. and MacLean, P. A., 1986. Development of hybrid aeolian dunes:

921 the William River dune field, northwest Saskatchewan, Canada. Canadian

922 Journal of Earth Sciences, 23: 1974-1990

923 Chapman, D.M., 1990. Aeolian sand transport - an optimized model. Earth 924 Surface Processes and Landforms, 751-760.

925 Christiansen, M.B. and Davidson-Arnott, R.G.D., 2004. Rates for landward sand 926 transport over the foredune at Skallingen, Denmark and the role of dune 927 ramps. Geografisk Tidsskrift, Danish Journal of Geography, 104(1): 27-36.

928 Coates, D. R. and Vitek, J.D., 1980. Thresholds in Geomorphology. Binghamton

929 Symposia in Geomorphology International Series. Allen and Unwin, $930 \quad$ Boston, xii, 498 p.:

931 Darke, I., Davidson-Arnott, R.G.D. and Ollerhead, J., 2009. Measurement of 932 beach surface moisture using surface brightness. Journal of Coastal 933 Research, 25, 248-256.

934 Davidson-Arnott, R.G.D. and Law, M.N., 1990. Seasonal patterns and controls 935 on sediment supply to coastal foredunes, Long Point, Lake Erie. In: K.F. $936 \quad$ Nordstrom, N.P. Psuty and R.W.G. Carter (Editors), Coastal Dunes: $937 \quad$ Form and Process. John Wiley \& Sons, pp. 177-20.

938 Davidson-Arnott, R.G.D. and Law, M.N., 1996. Measurement and prediction of 939 long-term sediment supply to coastal foredunes. Journal of Coastal $940 \quad$ Research, 12 pp. 654-663.

941 Davidson-Arnott, R.G.D., Yang, Y., Ollerhead, J., Hesp, P.A. and Walker, I.J., 942 2008. The effects of surface moisture on aeolian sediment transport 
threshold and mass flux on a beach. Earth Surface Processes and

$944 \quad$ Landforms, 33, $55-74$.

945 Davidson-Arnott, R.G.D. and Bauer, B.O., 2009. Aeolian sediment transport on a 946 beach: Thresholds, intermittency, and high frequency variability.

$947 \quad$ Geomorphology. 105, 117-126

948 Delgado-Fernandez, I., Davidson-Arnott, R.G.D. and Ollerhead, J., 2009.

949 Application of a remote sensing technique to the study of coastal dunes.

$950 \quad$ Journal of Coastal Research, 25 (5), 1160-1167.

951 Dong, Z., Wang, H., Liu, X. and Wang, X., 2004. The blown sand flux over a 952 sandy surface: a wind tunnel investigation on the fetch effect. $953 \quad$ Geomorphology, 57, 117-127.

954 Fryberger, S.G. and Dean, G., 1979. Dune forms and wind regime. In: E.D. $955 \quad$ McKee (Editor), Global Sand Seas, pp. 141-151.

956 Fryrear, D. W., Bilbro, J. D., Saleh, A., Schomberg, H., Stout, J. E., and Zobeck, 957 T. M., 2000. RWEQ: Improved Wind Erosion Technology. J. Soil Water $958 \quad$ Conserv. 55, p. 183

959 Gillette, D.A., Herbert, G., Stockton, P.H. and Owen, P.R., 1996. Causes of the 960 fetch effect in wind erosion, Earth Surf. Proc. Land. 21, 641-659.

961 Hesp, P.A., 1988a. Morphology, dynamics and internal stratification of some 962 established foredunes in southeast Australia. Journal of Sedimentary 963 Geology, 55, pp. 17-41.

964 Hesp, P.A., 1988b. Surfzone, beach and foredune interaction on the Australian 965 southeast coast. Journal of Coastal Research, 3, 15-25. 
966 Hesp, P. A., 2002. Foredunes and blowouts: initiation, geomorphology and 967 dynamics. Geomorphology, 48, 245-268.

968 Hesp, P.A., Davidson-Arnott, R.G.D., Walker, I.J. and Ollerhead, J., 2005. Flow 969 dynamics over a foredune at Prince Edward Island, Canada. $970 \quad$ Geomorphology, 65, 71-84.

971 Hotta, S., Kubota, S., Katori, S. and Horikawa, K., 1984. Sand transport by wind 972 on a wet sand surface. Proceedings of the 19th Coastal Engineering 973 Conference, ASCE, New York, pp. 1265-1281.

974 Hsu, 1974. Computing eolian sand transport from routine weather data. 975 Proceedings of the $14^{\text {th }}$ Conference on Coastal Engineering, ASCE, New $976 \quad$ York, 1619-1626.

977 Hunter, R.E., Richmond, B.M., Alpha, T.R., 1983. Storm-controlled oblique dunes 978 of the Oregon coast. Geological Society of America Bulletin, 94, 1450$979 \quad 1465$

980 Jackson, N.L. and Nordstrom, K.F., 1997. Effects of time-dependent moisture 981 content of surface sediments on aeolian transport rates across a beach, 982 Wildwood, New Jersey. U.S.A. Earth Surface Processes and 983 Landforms, 22: 611-621.

984 Kadib, A.L., 1964. Calculation procedure for sand transport by wind on natural 985 beaches, Miscellaneous paper 2, 64, US Army Coastal Engineering $986 \quad$ Research Center.

987 Kroon, A. and Hoekstra, P., 1990. Eolian sediment transport on a natural beach. 988 Journal of Coastal Research, 367-380. 
989 Law, M. N., 1989. Sand Transport from Beaches to Coastal Dunes. M.Sc.

$990 \quad$ Thesis, University of Guelph, $173 \mathrm{pp}$.

991 Lettau K. and Lettau, H., 1977. Exploring the World's Driest Climate. University of

992 Wisconsin-Madison, IES Report 101, 110-147.

993 Logie, M., 1982. Influence of roughness elements and soil moisture on the

994 resistance of sand to wind erosion. In: D.H. Yaalon (Editor), Aridic soils

995 and geomorphic processes. Catena Supplement 1, Braunschweig, 161-

996173.

997 McKenna Neuman C, Muljaars Scott M. 1998. A wind tunnel study of the

$998 \quad$ influence of pore water on aeolian sediment transport. Journal of Arid

$999 \quad$ Environments 39, 403-419.

1000 McKenna Neuman, C. and Nickling, W.G., 1989. A theoretical and wind tunnel

1001 investigation of the effects of capillary water on the entrainment of

1002 sediment by wind. Canadian Journal of Soil Science, pp. 79-96.

1003 Namikas, S.L. and Sherman, D.J., 1995. A review of the effects of surface

1004 moisture content on aeolian sand transport. In: V.P. Tchakerian (Ed.),

1005 Desert Aeolian Processes. Chapman and Hall Ltd., London, 269-293.

1006 Nickling, W.G. and Davidson-Arnott, R.G.D., 1990. Aeolian sediment transport on

1007 beaches and coastal sand dunes. In: Davidson-Arnott, R.G.D. (Ed.),

1008 Proceedings of the Symposium on Coastal Sand Dunes, National

1009 Research Council of Canada, 1-35. 
1010 Nordstrom, K. F. and Jackson, N. L., 1993. The role of wind direction in eolian 1011 transport on a narrow sand beach. Earth Surface Processes and $1012 \quad$ Landforms, 18, 675-685.

1013 Ollerhead, J., Johnson, P., Davidson-Arnott, R. G. D., Walker, I., and Hesp, P. 1014 A., 2003. Sediment supply to coastal foredunes, Greenwich Dunes. 1015 Proceedings Canadian Coastal Conference, CCSEA, pp. 12.

1016 Psuty, N.P., 1988a. Sediment budget and dune/beach interaction. Journal of $1017 \quad$ Coastal Research, Special Issue 3, pp. 1-4.

1018 Pusty, N.P. (Ed.), 1988b. Dune/Beach interaction. Journal of Coastal Research, 1019 Special Issue No. 3, 136 pp.

1020 Ruz, M.H. and Meur-Ferec, C., 2004. Influence of high water levels on aeolian 1021 sand transport: upper beach/dune evolution on a macrotidal coast, 1022 Wissant Bay, northern France. Geomorphology, 60, 73-87.

1023 Sarre, R.D., 1987. Aeolian sand transport, Progress in Physical Geography, 157$1024 \quad 182$.

1025 Sarre, R.D., 1989. Aeolian sand drift from the intertidal zone on a temperate 1026 beach: potential and actual rates. Earth Surface Processes and $1027 \quad$ Landforms, 247-258.

1028 Sherman, D.J. and Bauer, B.O., 1993. Dynamics of beach-dune systems. 1029 Progress in Physical Geography, 413-447.

1030 Sherman, D.J. and Hotta, S., 1990. Aeolian sediment transport: theory and 1031 measurement. In: K.F. Nordstrom, N.P. Psuty and R.W.G. Carter 
1032

1033

1034

1035

1036

1037

1038

1039

1040

1041

1042

1043

1044

1045

1046

1047

1048

1049

1050

1051

1052 Wiggs, G.F.S., Baird, A.J. and Atherton, R.J., 2004b. The dynamic effects of 1053 moisture on the entrainment and transport of sand by wind. 1054 Geomorphology, pp. 13-30.

(Editors), Coastal Dunes: Process and Morphology. John Wiley and Sons, New York, pp. 17-37.

Short, A.D. and Hesp, P.A., 1982. Wave, beach and dune interactions in southeast Australia. Marine Geology, 48, 259-284.

Spies, P.J. and McEwan, I.K., 2000. Equilibration of saltation. Earth Surface processes and Landforms, pp. 437-453.

Stout, J.E. 1990. Wind erosion within a simple field. T. ASAE 33, 1597-1600.

Wahid, A.H., 2008. GIS-Based modelling of wind-transported sand on the Qaa Plain Beach, Southwestern Sinai, Egipt. Journal of Coastal Research, 24 (4), pp. 936-943.

Walker, I.J., Hesp, P.A., Davidson-Arnott, R.G.D. and Ollerhead, J., 2003. Topographic effects on airflow over a vegetated foredune: Greenwich Dunes, Prince Edward Island, Canada. Proceedings Coastal Sediments '03. ASCE, New York, pp. 15.

Walker, I. J., Hesp, P.A., Davidson-Arnott, R.G.D., and Ollerhead, J., 2006. Topographic Steering of Alongshore Airflow over a Vegetated Foredune: Greenwich Dunes, Prince Edward Island, Canada. Journal of Coastal Research, 22, 1278-1291.

Wiggs, G.F.S., Atherton, R.J. and Baird, A.J., 2004a. Thresholds of aeolian sand transport: establishing suitable values. Sedimentology, 51, 95-108. 
1055 Wolman, M.G. \& W.P Miller. 1960. Magnitude and frequency of forces in 1056 geomorphic processes. Journal of Geology, 68, 54-74.

1057 Yang, Y. and Davidson-Arnott, R.G.D., 2005. Rapid Measurement of Surface

1058 Moisture Content on a Beach. Journal of Coastal Research, 21, 447-452.

1059

1060 List of Figures
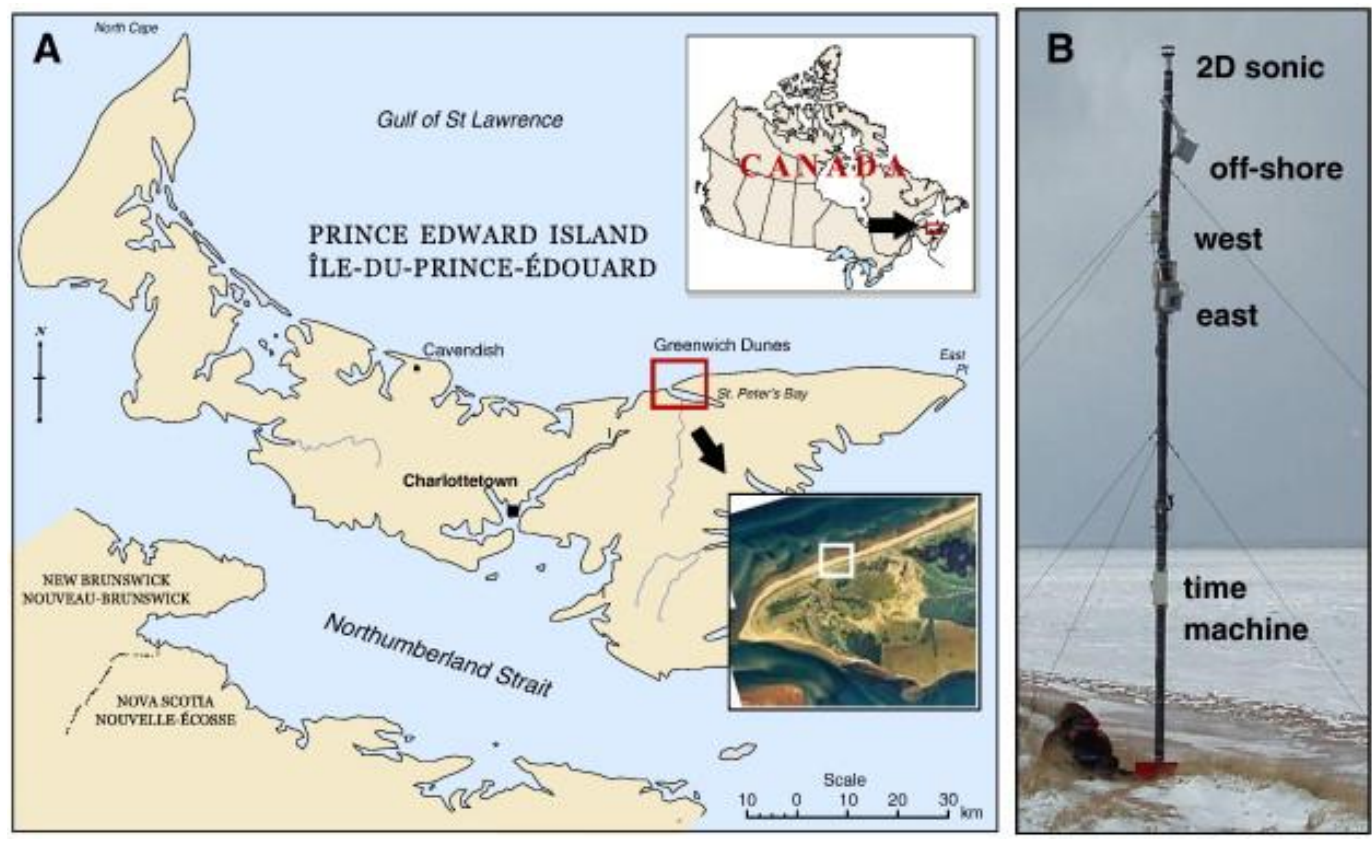

Fig. 1. A) Location of study area; B) Principal components of the camera system and 2-Dimensional Windsonic anemometer located on top of the $6 \mathrm{~m}$ mast (elevation over the beach surface of approximately $14 \mathrm{~m}$ ). 

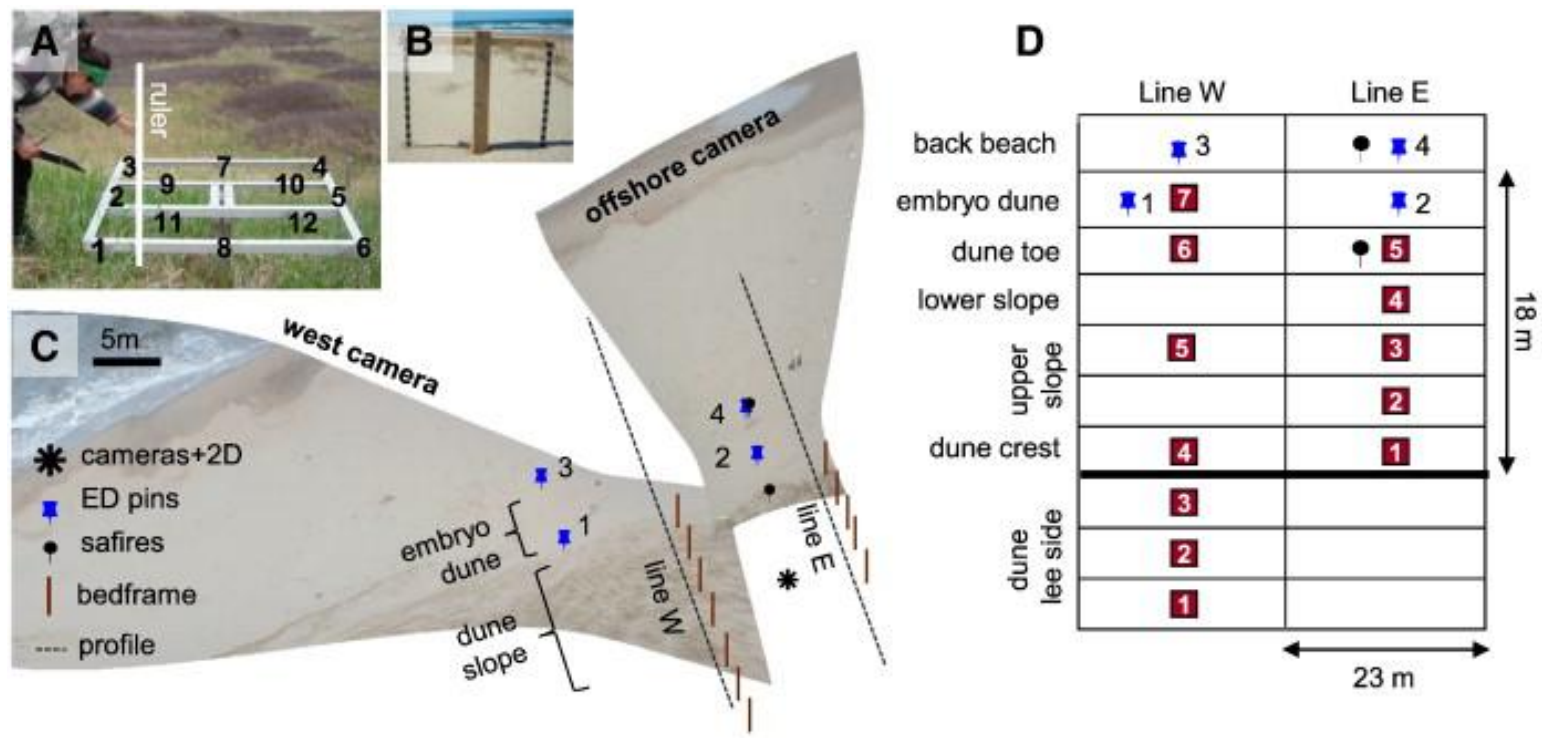

Fig. 2. A) Bedframe device deployed at a bedframe post at the dune. The average of the distance from the ground to the 12 points marked in the image provides data on surface elevation change at that location (Ollerhead et al., 2003). B) Erosiondeposition (ED) pin; C) Location of transport measurement points and survey profiles with respect to the camera system; D) Distribution of bedframe posts along line $\mathrm{E}$ and $\mathrm{W}$, covering a total area of $46 \mathrm{~m}$ alongshore $\mathrm{x} 18 \mathrm{~m}$ across the dune. Each bedframe post represented an area of $23 \mathrm{~m}$ alongshore $\times 3 \mathrm{~m}$ cross-shore. No bedframe posts were located on line E beyond the dune crest. Bedframe posts 1-3 in line $W$ were used for monitoring but not in actual calculations (Section 7.1). Safires and ED pins are included in the closest grid cell. Topographic details of lines $\mathrm{E}$ and $\mathrm{W}$ are included inFig. 8.

1062 

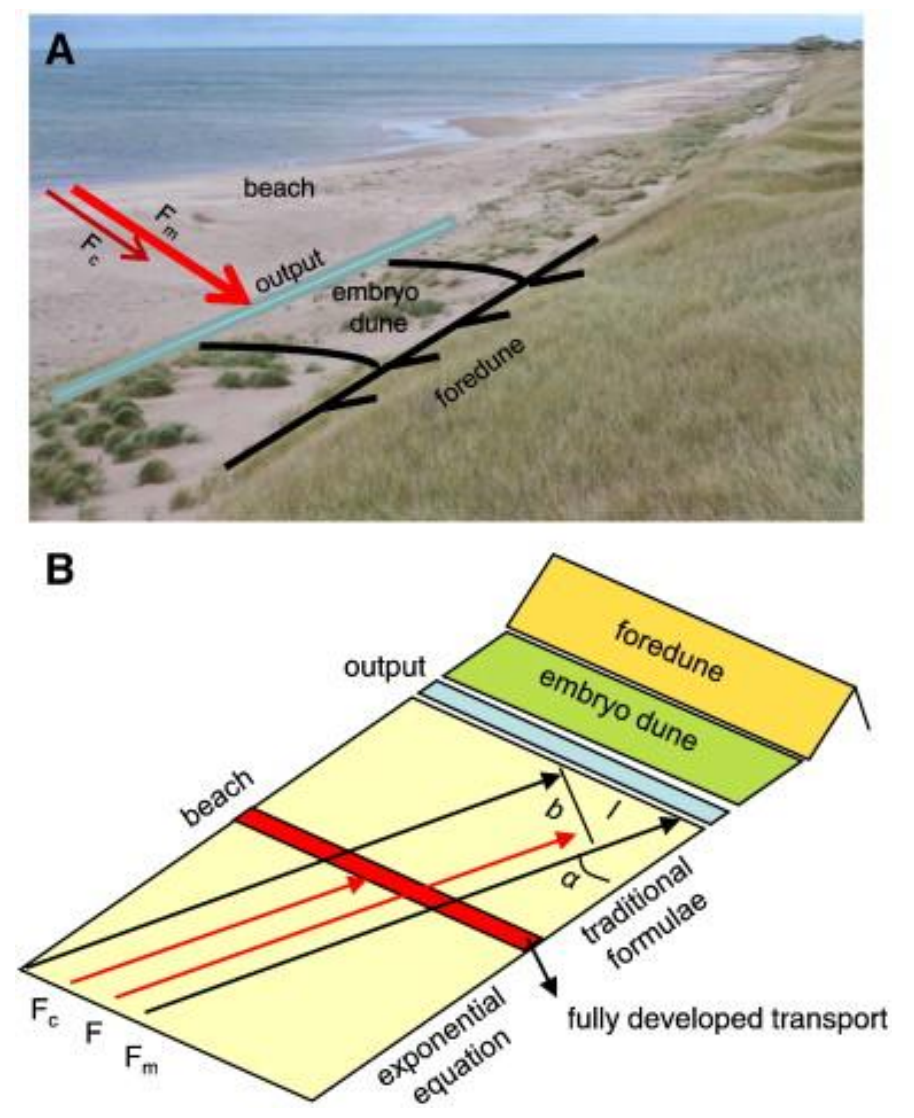

Fig. 3. Framework for modelling aeolian sediment output from the beach to the dune based on the study by Bauer and Davidson-Arnott (2003). A) Image taken by the east-facing camera at Greenwich, showing the location of the output area; B) Scheme for modelling. The red line on the beach surface indicates the area where transport is fully developed for an incoming wind speed. Fm is the maximum available fetch, $F c$ is the critical fetch and $\alpha$ is the angle of wind approach. Traditional formulae to predict sediment transport rates may be applied where $F>F C$, whilst transport follows an exponential relation with distance where $F<F c$. 

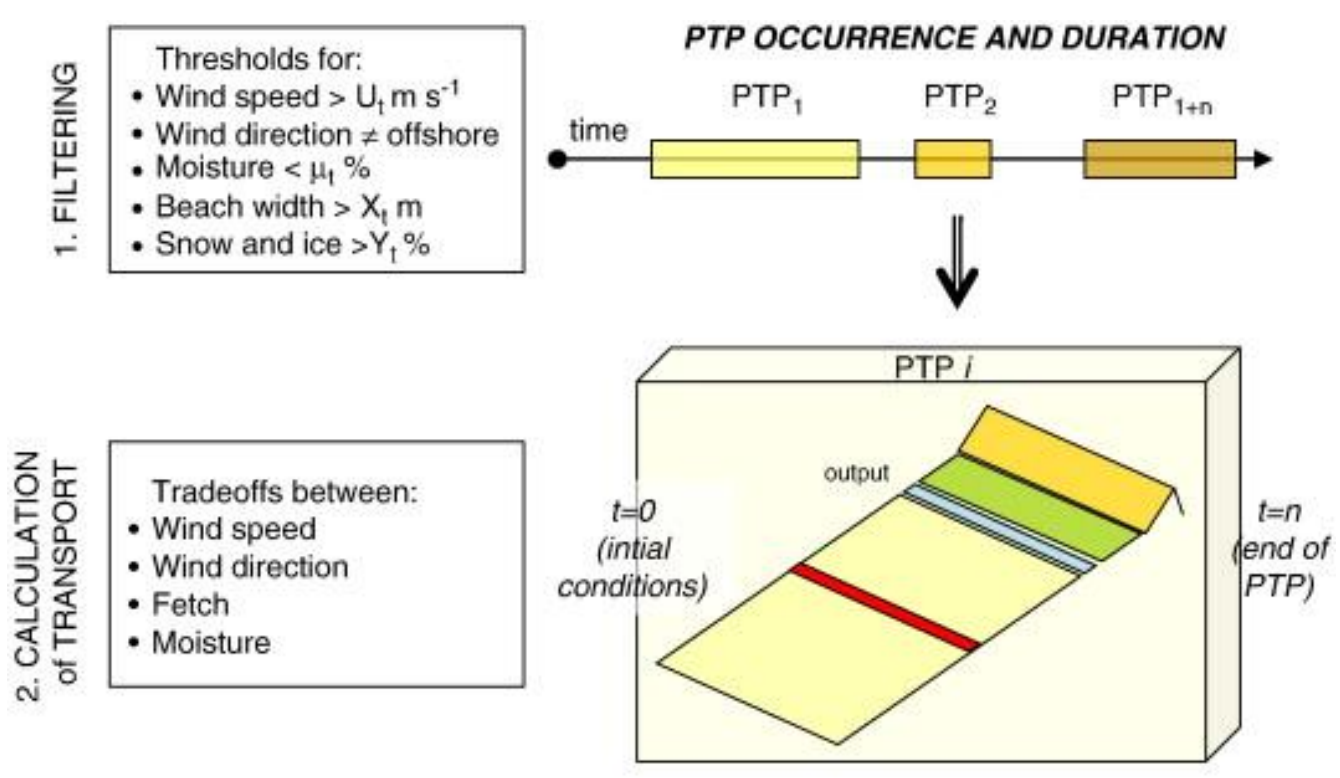

PTP MAGNITUDE

Fig. 4. Modelling approach following two steps: 1) the filtering reduces the time series and isolates potential transport periods (PTPs) providing valuable information about potential occurrence and duration of transport events and 2) calculation of transport focuses on particular PTPs, where the magnitude of sediment input to the foredunes is computed considering the fetch and the cosine effects and moisture content. This step may allow incorporation of the spatial variability of key factors, such as variations of beach width and moisture content over a particular event. 


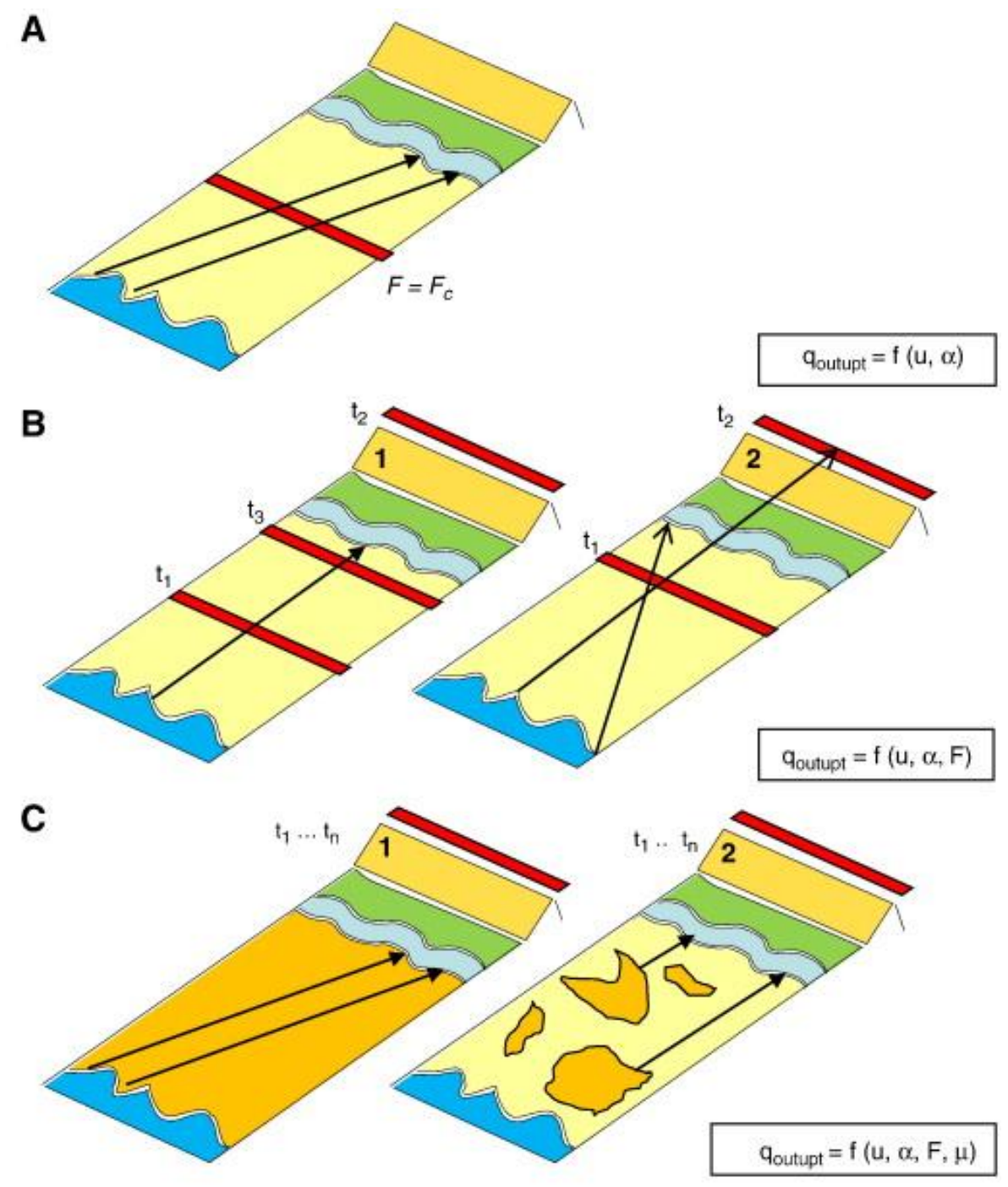

Fig. 5. Modelling scenarios for calculating sediment output from the beach (qoutput) and hypothetical examples of potential transport periods (PTPs). Note that a red band beyond the foredune crest indicates that the fetch distance is shorter than the critical fetch $(F<F C)$ at the output area and thus the fetch effect needs to be considered. A) Type A PTP: transport at the output area is solely based on wind speed and direction and may be predicted using Bagnold-type equations (e.g., oblique-onshore winds over a dry surface); B) Type B PTPs: the fetch effect needs to be considered during tzperiods. The beach surface is dry 
but the area (red line) where $F=F c$ changes spatially because of increases on wind speed (B1) or changes in the angle of wind approach (B2). B1 shows an example of a situation with a low wind speed ( $\left.\mathrm{t}_{1}\right)$ becoming increasingly strong ( $\mathrm{t}_{2}$ - longer $F c$ ), followed by a final period of low wind speed $\left(\mathrm{t}_{3}\right)$. B2 shows an example of a strong oblique wind $\left(\mathrm{t}_{1}\right)$ shifting to directly onshore $\left(\mathrm{t}_{2}-F_{C}\right.$ remains constant but $F$ decreases during onshore winds). C) Type C PTPs: both the fetch effect and moisture (in orange) need to be considered. Uniform moisture (C1) increases the $F c$ and thus transport may never fully develop at the beach. Moisture patches (C2) reduce the available $F$ between the onset of transport and the output area.

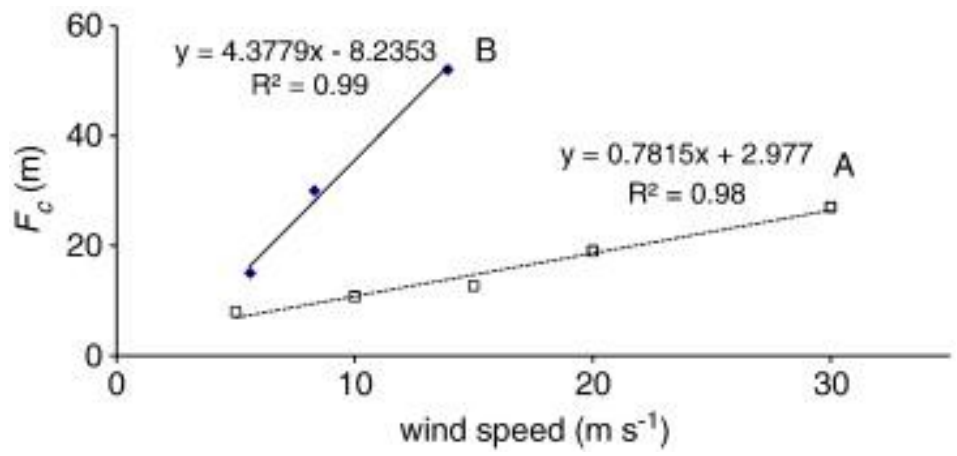

Fig. 6. Correlation between wind speed and critical fetch $(F c)$ for the data presented by A) Spies and McEwan (2000) and B) Davidson-Arnott and Law (1996). Note that wind speed (U) for curve A has been calculated from friction velocities $\left(\mathrm{u}^{*}\right)$ reported by Spies and McEwan using the Law of the Wall $(U=\ln$ $\left.\left(\mathrm{z} / \mathrm{z}_{0}\right) \mathrm{u}^{*} / \mathrm{k}\right)$ and assuming a grain size of $0.25 \mathrm{~mm}$. 


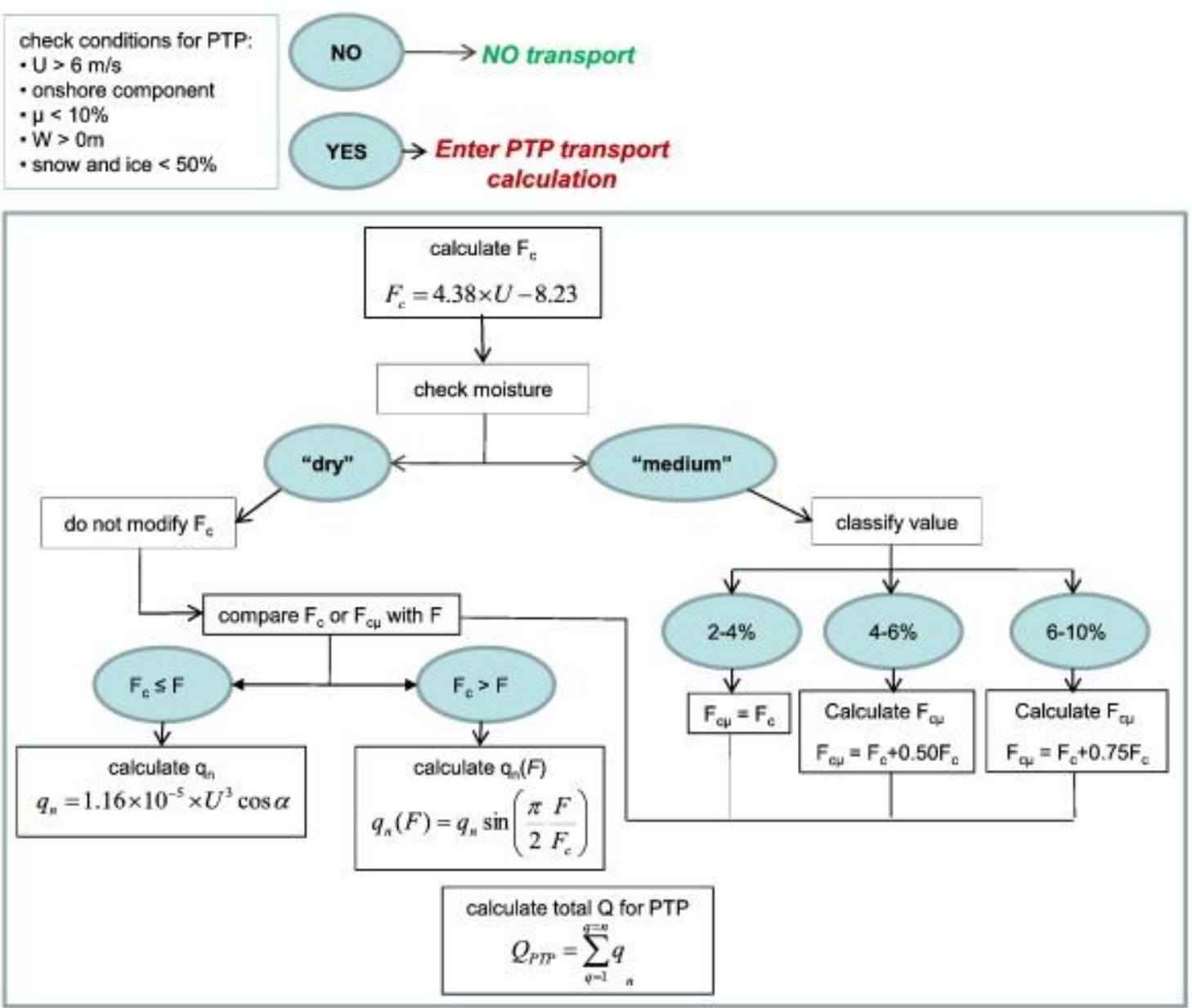

Fig. 7. Modelling steps and analytical procedure applied to hourly records of wind speed $(U)$ and direction $(\alpha)$, fetch distance $(F)$, critical fetch distance $(F C)$ and moisture $(\mu)$ for potential transport periods (PTPs) isolated by the filtering. 

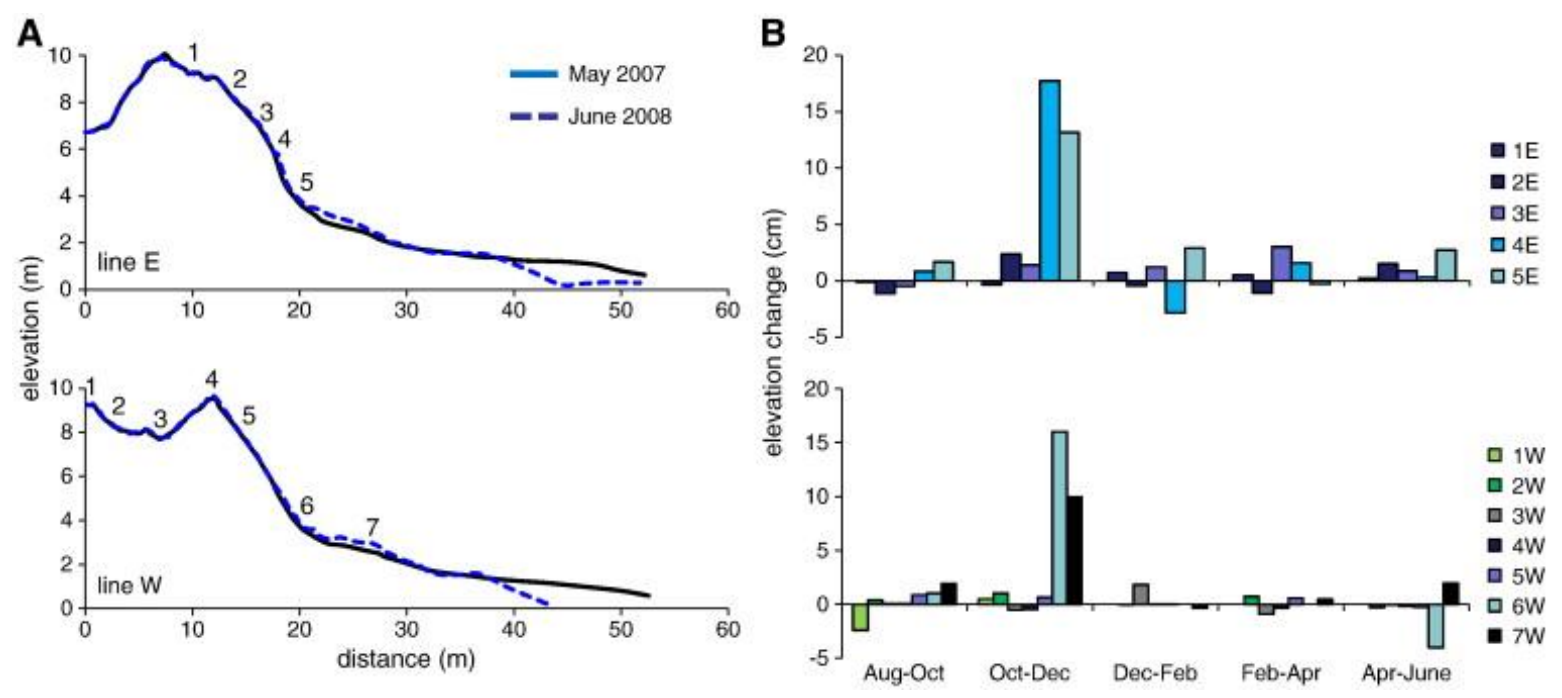

Fig. 8. A) Topographic profiles on May 2007 and June 2008. The numbers over the profiles show the location of bedframe posts; B) Bi-monthly net changes from August 2007 to June 2008 detected with the bedframe technique. Note that the largest change on the foredune stoss slope is of $+3 \mathrm{~cm}$ in post $3 \mathrm{E}$. Most significant changes occurred from October to December 2007 at the lower sections of the dune (posts 4-5E and 6-7 W).
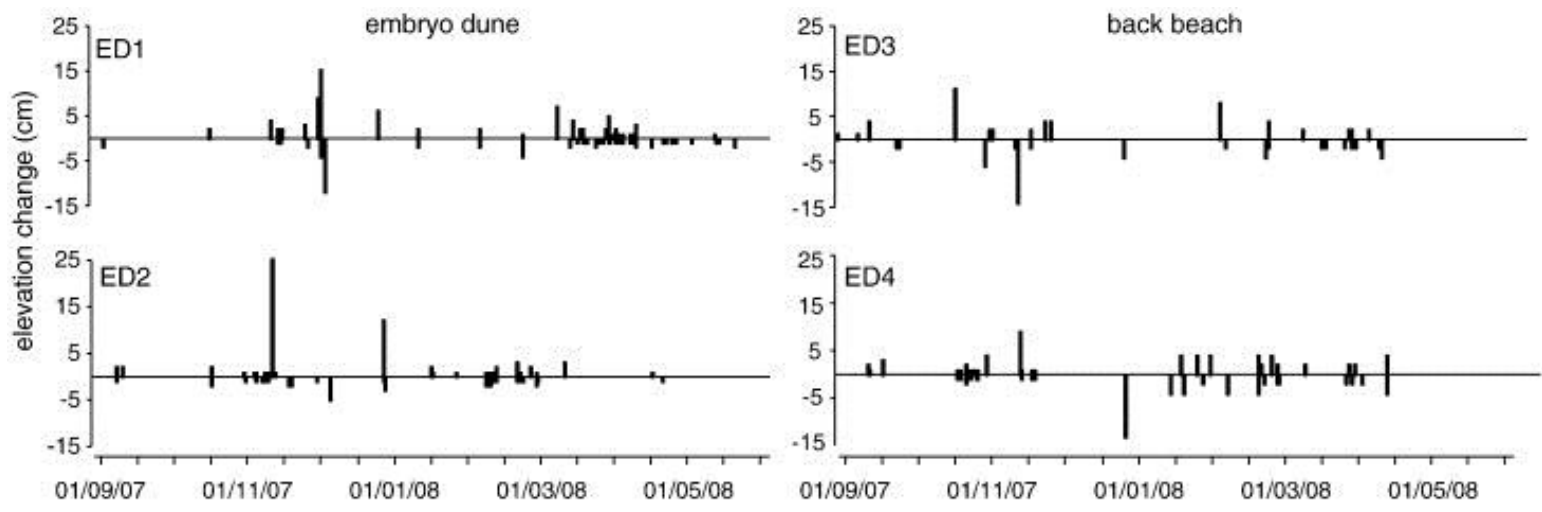

Fig. 9. Erosion-deposition (ED) pin records show several periods of accumulation and erosion. The majority of changes are of less than $\pm 5 \mathrm{~cm}$, but there are several hourly changes of $\pm 15 \mathrm{~cm}$ and a single record of $+25 \mathrm{~cm}$ associated with the in 
November 9, 2007 (Section 7.3).

1069
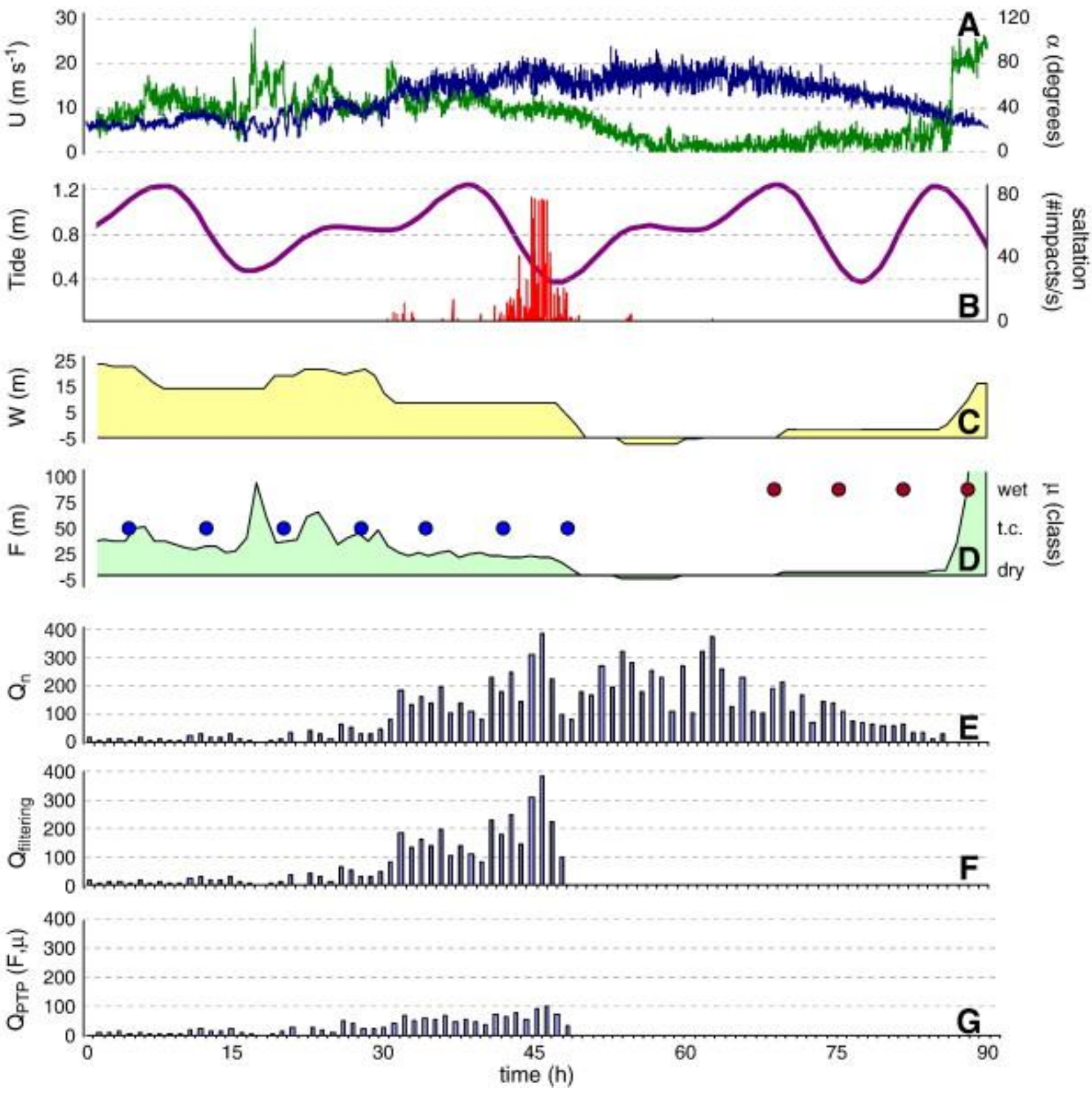

Fig. 10. Modelling output for a 90-hours storm approaching Greenwich from the North on November 9, 2007. A) 2-min records of wind speed (U) and direction ( $\alpha$ ); B) saltation intensity and tide elevation; C) beach width (W); D) fetch distance (F) determined by beach width and wind direction, and classified moisture values $(\mu)$; E) hourly transport 
based on wind speed and direction $\left(Q_{n}\right) ; F$ ) output of the filtering step ( $Q_{\text {filtering); }}$ ) output of the calculation of transport over the isolated potential transport periods (QPTP) including fetch distance and moisture. Transport in E-F is expressed in $\mathrm{kg} \mathrm{m}^{-1}$.

1070

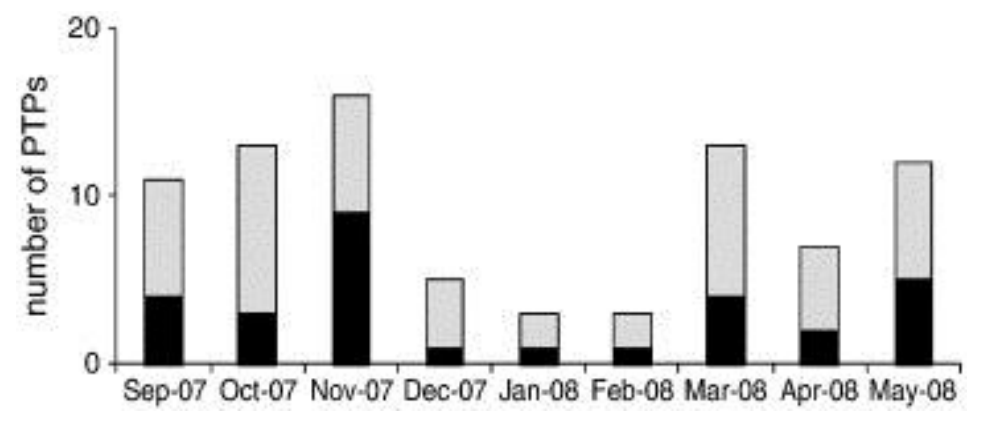

Fig. 11. Isolated potential transport periods (PTPs) where transport was observed (black) and where transport was not developed (grey). 